\title{
Lower Cretaceous Rodby and Palaeocene Lista Shales: Characterisation and Comparison of Top-Seal Mudstones at Two Planned CCS Sites, Offshore UK
}

\author{
Richard H. Worden ${ }^{1, *} \mathbb{C}^{\mathbb{D}}$, Michael J. Allen ${ }^{1}{ }^{\mathbb{D}}$, Daniel R. Faulkner ${ }^{1}$, James E. P. Utley ${ }^{1}$,

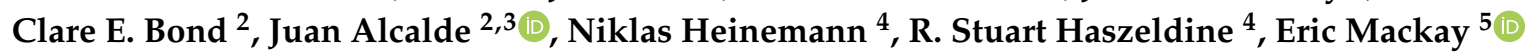 \\ and Saeed Ghanbari ${ }^{5}$ \\ 1 Department of Earth, Ocean and Ecological Sciences, University of Liverpool, Jane Herdman Building, \\ 4 Brownlow Street, Liverpool, Merseyside L69 3GP, UK; mjallen@liverpool.ac.uk (M.J.A.); \\ Faulkner@liverpool.ac.uk (D.R.F.); james.utley@liverpool.ac.uk (J.E.P.U.) \\ 2 Department of Geology and Petroleum Geology, University of Aberdeen, Aberdeen AB24 3FX, UK; \\ clare.bond@abdn.ac (C.E.B.); jalcalde@ictja.csic.es (J.A.) \\ 3 Geosciences Barcelona, CSIC, Lluis Sole Sabaris s/n, 08028 Barcelona, Spain \\ 4 School of Geosciences, University of Edinburgh, Grant Institute, West Main Road, Edinburgh EH9 3JW, UK; \\ n.heinemann@ed.ac.uk (N.H.); stuart.haszeldine@ed.ac.uk (R.S.H.) \\ 5 Institute of Geoenergy Engineering, Heriot-Watt University, Riccarton, Edinburgh EH14 4AS, UK; \\ E.J.Mackay@hw.ac.uk (E.M.); s.ghanbari@hw.ac.uk (S.G.) \\ * Correspondence: r.worden@liv.ac.uk
}

Received: 27 May 2020; Accepted: 30 July 2020; Published: 3 August 2020

Abstract: Petroleum-rich basins at a mature stage of exploration and production offer many opportunities for large-scale Carbon Capture and Storage (CCS) since oil and gas were demonstrably contained by low-permeability top-sealing rocks, such as shales. For CCS to work, there must be effectively no leakage from the injection site, so the nature of the top-seal is an important aspect for consideration when appraising prospective CCS opportunities. The Lower Cretaceous Rodby Shale and the Palaeocene Lista Shale have acted as seals to oil and gas accumulations (e.g., the Atlantic and Balmoral fields) and may now play a critical role in sealing the Acorn and East Mey subsurface carbon storage sites. The characteristics of these important shales have been little addressed in the hydrocarbon extraction phase, with an understandable focus on reservoir properties and their influence on resource recovery rates. Here, we assess the characteristics of the Rodby and Lista Shales using wireline logs, geomechanical tests, special core analysis (mercury intrusion) and mineralogical and petrographic techniques, with the aim of highlighting key properties that identify them as suitable top-seals. The two shales, defined using the relative gamma log values (or Vshale), have similar mean pore throat radius (approximately $18 \mathrm{~nm}$ ), splitting tensile strength (approximately $2.5 \mathrm{MPa}$ ) and anisotropic values of splitting tensile strength, but they display significant differences in terms of wireline log character, porosity and mineralogy. The Lower Cretaceous Rodby Shale has a mean porosity of approximately $14 \%$, a mean permeability of $263 \mathrm{nD}\left(2.58 \times 10^{-19} \mathrm{~m}^{2}\right)$, and is calcite rich and has clay minerals that are relatively rich in non-radioactive phases such as kaolinite. The Palaeocene Lista Shale has a mean porosity of approximately $16 \%$ a mean permeability of $225 \mathrm{nD}$ $\left(2.21 \times 10^{-19} \mathrm{~m}^{2}\right)$, and is calcite free, but contains abundant quartz silt and is dominated by smectite. The $2 \%$ difference in porosity does not seem to equate to a significant difference in permeability. Elastic properties derived from wireline log data show that Young's modulus, material stiffness, is very low ( $5 \mathrm{GPa}$ ) for the most shale (clay mineral)-rich Rodby intervals, with Young's modulus increasing as shale content decreases and as cementation (e.g., calcite) increases. Our work has shown that Young's modulus, which can be used to inform the likeliness of tensile failure, may be predictable based on routine gamma, density and compressive sonic logs in the majority of wells where the less common shear logs were not collected. The predictability of Young's modulus from routine well log 
data could form a valuable element of CCS-site top-seal appraisals. This study has shown that the Rodby and Lista Shales represent good top-seals to the Acorn and East Mey CCS sites and they can hold $\mathrm{CO}_{2}$ column heights of approximately $380 \mathrm{~m}$. The calcite-rich Rodby Shale may be susceptible to localised carbonate dissolution and increasing porosity and permeability but decreasing tendency to develop fracture permeability in the presence of injected $\mathrm{CO}_{2}$, as brittle calcite dissolves. In contrast, the calcite-free, locally quartz-rich, Lista Shale will be geochemically inert to injected $\mathrm{CO}_{2}$ but retain its innate tendency to develop fracture permeability (where quartz rich) in the presence of injected $\mathrm{CO}_{2}$.

Keywords: Rodby Shale; Lista Shale; carbon capture and storage; North Sea; wireline logs; splitting tensile stress; mercury intrusion porosimetry; SEM-EDS; quantitative mineralogy; geomechanical properties; Young's modulus; $\mathrm{CO}_{2}$ column height

\section{Introduction}

Mudstones represent a crucial part of most Carbon Capture and Storage (CCS) sites given that they represent the most common top-seal of the structure. Many CCS sites under consideration are either old oil and gas fields or deep saline aquifers [1]. Projects that plan for injection of $\mathrm{CO}_{2}$ into old oil and gas fields will fill the reservoirs and become trapped below the mudstone top-seal. However, there is demonstrably no long-term benefit in injecting $\mathrm{CO}_{2}$ into the subsurface if it is going to leak back to surface within a relatively short $(10,000 \mathrm{yr})$ timescale. Operators are required to demonstrate that their operations are carried out in a safe manner, and that the risk of leakage is minimum, in order to ensure that CCS is effective in mitigating climate change and that it is acceptable for the society [2]. For example, Harding, et al. [3] showed that if $0.1 \%$ of the injected $\mathrm{CO}_{2}$ leaks each year, then most of the injected $\mathrm{CO}_{2}$ will escape from the subsurface within approximately 2000 years, thus negating the benefits of long-term greenhouse gas disposal.

Leakage of $\mathrm{CO}_{2}$ from subsurface storage sites could occur by a range of mechanisms including (1) fracturing of the near well-bore region during high-pressure $\mathrm{CO}_{2}$ injection (especially if the fractures penetrate the top-seal), (2) incomplete cement seals between the borehole's steel liner and the borehole wall of the injection well, (3) transiently-opened natural fractures in the top-seal or induced fracturing of the top-seal, (4) dissolution and weakening of top-seal lithologies, (5) unplugged abandoned wells along the $\mathrm{CO}_{2}$ plume's migration route, and (6) stratigraphic updip flow to the land or seabed via long-range migration if capillary trapping is not sufficiently effective [4]. Many of these leakage mechanisms involve the top seal, the integrity of which is thus essential to arrest leakage. The petrophysical, geomechanical and geochemical properties of mudstones control their integrity via (1) their ability to contain the injected $\mathrm{CO}_{2}$ gas plume, (2) their responses to elevated fluid pressure (ductile deformation versus fracturing) and (3) the response of minerals in the mudstone to elevated $\mathrm{CO}_{2}$ partial pressure (inert versus mineral dissolution or precipitation and resulting feedbacks on petrophysical or geomechanical properties). Thus, it is clearly important to understand the geomechanical and geochemical responses of the top-seal in any prospective of potential carbon storage sites to high-pressure $\mathrm{CO}_{2}$ injection.

The work reported here is part of an assessment of the seal characteristics for two potential carbon storage sites in the UK North Sea. It forms part of the Accelerating Carbon Technologies (ACT) Acorn Carbon Capture and Storage (CCS) Project, under the ERA-NET Horizon 2020 programme, project 271500, and was jointly funded by the Department for Business, Energy and Industrial Strategy, United Kingdom; the Research Council of Norway; the Netherlands Enterprise Agency. The project aimed to implement a low-cost, scalable full-chain CCS hub that will capture $\mathrm{CO}_{2}$ emissions from the St Fergus Gas Terminal in North East Scotland and subsequently store the $\mathrm{CO}_{2}$ at an offshore storage site under the North Sea [5,6]. The project is comprised of both technical and non-technical activities including scientific research, with the aim to develop the technical specifications for an ultra-low-cost, 
integrated CCS hub that can be scaled up at marginal cost [5]. The Acorn project involves the use of two storage sites (Figure 1A) within open saline aquifers: the Lower Cretaceous Acorn (Figure 1B) and the Palaeocene East Mey (Figure 1C) CCS sites. The Acorn site is a portion of the Captain Sandstone, which has been appraised for potential CCS in different projects [7,8]. Acorn will serve as the primary store and could host up to $152 \mathrm{Mt} \mathrm{CO}_{2}$. The East Mey site belongs to the greater Mey Sandstone and has been developed as a secondary option to act as an additional site for upscaling stages or as a backup site in case of an emergency.
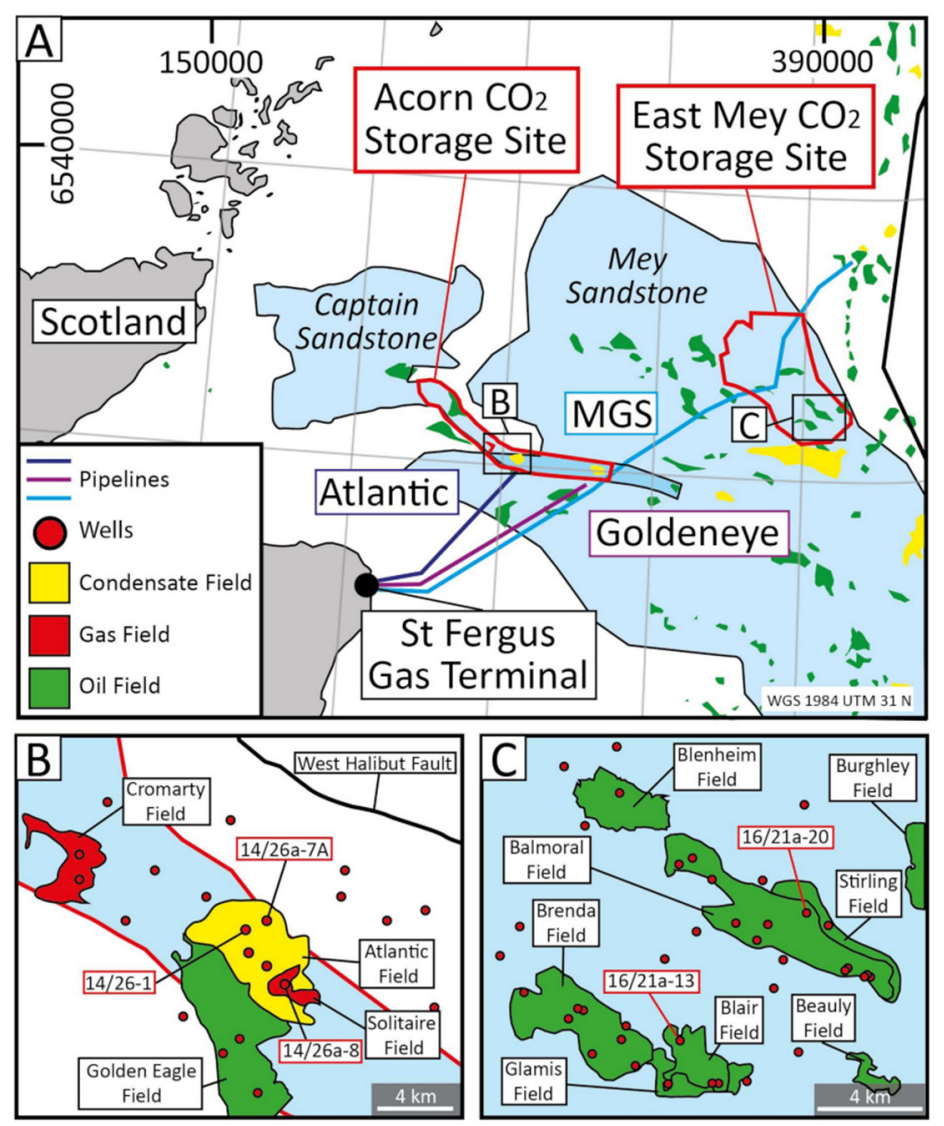

Figure 1. (A) Location of Acorn and East Mey $\mathrm{CO}_{2}$ Storage Sites in the study area in the western North Sea. The extents of the Captain Sandstone Member and the Mey Sandstone are shown in blue. The extents of the Acorn $\mathrm{CO}_{2}$ and the East Mey Storage Sites are highlighted in red. Petroleum fields and pipelines extending from the St Fergus Gas Terminal to the study areas are included. The pipelines may be repurposed to deliver $\mathrm{CO}_{2}$ offshore for subsurface storage. (B) Map of the Acorn site for the Atlantic and related fields with well locations indicated. (C) Map of the East Mey site for the Balmoral and related fields with well locations indicated. All figures modified after Williams, Fellgett and Quinn [7], Pale-Blue-Dot-Energy [9], Pale-Blue-Dot-Energy [10].

This study addresses the characterisation of the mudstone top-seals to the planned Acorn and East Mey CCS sites using a combination of wireline logs from mudstones (and reservoirs), core analysis, geomechanical testing and mineralogical and petrographic analyses. Much of the data are only available because the Moray Firth Basin and the Central North Sea Basin has been a site of active oil and gas exploration and production for the last 40 to 50 years. These legacy data have proved invaluable throughout the Acorn project and serve as a model for how to proceed with CCS projects in oil- and gas-producing regions [6]. Furthermore, oil and gas exploration and production companies (specifically CNOOC Petroleum Europe Ltd. (London, UK), Premier Oil and Repsol-Sinopec) have been more than willing to assist in this work by freely providing valuable core, cuttings and data. 


\section{Background Geology}

The following section summarises, in ascending stratigraphic order, the key aspects of the lithostratigraphy and geology of the Acorn and East $\mathrm{Mey} \mathrm{CO}_{2}$ Storage Sites and their bounding lithologies; see Figure 1 for location map. The lithostratigraphy for this part of the Central North Sea is illustrated in the synthetic stratigraphic column Figure 2.

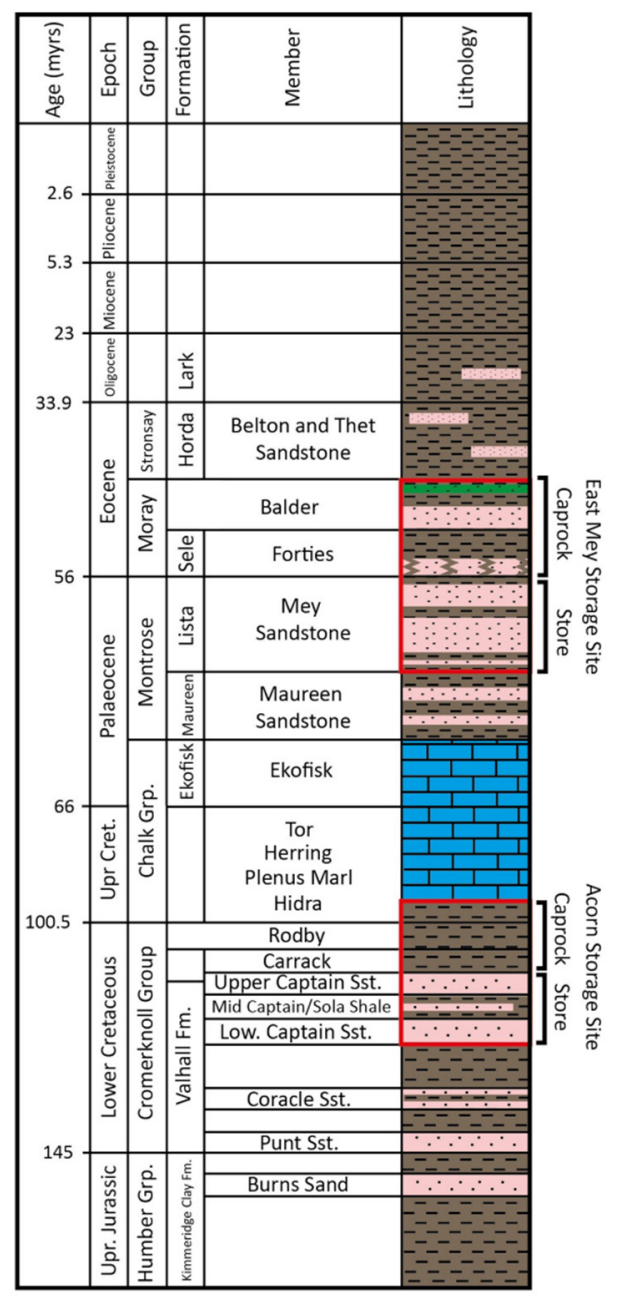

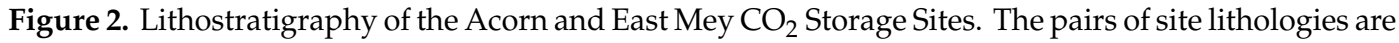
highlighted in red. The Captain Sandstone Member, part of the Lower Cretaceous Valhall Formation, is the reservoir for the Acorn Site which has the Rodby and Carrack Formations as the top-seal. The Captain Sandstone contains the intraformational Sola Shale that may result in internal compartmentalisation of the Captain Sandstone reservoir. The Mey Sandstone Member, part of the Palaeocene Lista Formation, is the reservoir for the East Mey Site, which has an overlying Lista Formation Shale, together with Eocene Sele Formation, as the top-seal. The approximately 56 Ma East Mey CCS reservoirs and top-seals are at approximately $7100 \mathrm{ft}$ true vertical depth. The approximately $100 \mathrm{Ma}$ Acorn site has undergone slower sedimentation over a longer period, than the East Mey site, since the older Acorn reservoirs and top-seals are at approximately $6500 \mathrm{ft}$ true vertical depth. Modified after Pale-Blue-Dot-Energy [9], Pale-Blue-Dot-Energy [10].

The Lower Cretaceous Captain Sandstones and the Sola, Carrack and Rodby Shales are the key storage and caprock lithologies, respectively, for the Acorn $\mathrm{CO}_{2}$ Storage Site. At the top of the Upper Jurassic, stratigraphically below the Acorn $\mathrm{CO}_{2}$ Storage Site, lies the Kimmeridge Clay Formation, composed dominantly of marine hemipelagic mudstones, which are the hydrocarbon source rocks for many petroleum fields in the region. The Lower Cretaceous Cromer Knoll Group is composed of 
turbiditic sand units, which include the Punt, Coracle and Captain Sandstones; the Captain Sandstone Member is the planned storage site for the Acorn CCS site. The Captain Sandstone, approximately $100 \mathrm{Ma}$, is interbedded with hemipelagic shales which occur throughout the formation, including the Mid-Captain Sola Shale, Carrack and Rodby Shales [11]. The Sola Shale is interbedded within the Captain Sandstone Member with the Carrack and the Rodby Shales locally occurring as top-seals. Overlying the Acorn Storage Site is the Upper Cretaceous Chalk Group, which divides into: the Plenus Marl Formation, composed of black anoxic calcareous mudstones; the Hidra Formation, composed of argillaceous limestones, marls and mudstones; and the Ekofisk, Tor, Hod and Herring Formations, composed of limestone interbedded with claystone and marl beds.

Up sequence, the lowermost Cenozoic contains the Maureen Formation, which is composed of amalgamated gravity flow sands with reworked basinal chalk and interbedded siltstones. Overlying the Maureen Formation is the approximately 56 Ma Lista Formation, which is composed of a marine basin to outer shelf mudstone, known as the Lista Shale, that is interbedded with submarine gravity flow sandstones. The Lista Formation sandstones occur across the Outer Moray Firth and Central Graben and are known as the Mey Sandstone Member. The Mey Sandstone Member has local names such as the Andrew and Balmoral Sandstones [12,13]. The Mey Sandstone is the planned reservoir unit for the East Mey CCS site. The top-seal for the East Mey site is the Lista Shale but the Lista Shale also occurs interbedded between the sandstone beds planned for CCS.

The Quaternary Nordland Group is at the top of the succession, and is composed of undifferentiated mudstones, claystones and localised marls [14].

The burial and thermal histories of the Acorn and East Mey sites (Figure 2) are relatively simple, with continued sediment deposition and no significant periods of uplift and erosion from the time of deposition of the Lower Cretaceous (Acorn) and Palaeocene (East Mey) to the present day. The Acorn CCS site, close to the Atlantic oil field in North Sea block 14/26 (Figures 1B and 2), is buried to approximately 6000 to $6800 \mathrm{ft}$ (approximately 1800 to $2000 \mathrm{~m}$ ), and this equates to a present-day temperature of approximately 60 to $70{ }^{\circ} \mathrm{C}$. The Palaeocene East Mey target CCS site, close to the Balmoral oil field in North Sea block 16/21 (Figures 1C and 2), is also buried to approximately 6000 to $7200 \mathrm{ft}$ (approximately 1800 to $2100 \mathrm{~m}$ ), equating to a present day temperature of approximately 60 to $70{ }^{\circ} \mathrm{C}$. The Lower Cretaceous (113-100 Ma) Acorn site has been buried and heated more slowly than the Palaeocene (66-55 Ma) East Mey site but they have both reached about the same depth and temperature.

\section{Methods}

\subsection{Samples and Data}

The Atlantic Field, initially operated by BG Group, and then subsequently operated by CNOOC Petroleum Europe Ltd. (London, UK), was selected for part of this study as it is within the planned Acorn CCS site. Three wells, 14/26-1, 14/26a-7A and 14/26a-8 (Figure 1B), were high graded here for detailed study since they had core that was collected from both the Captain Sandstone Member, intraformational Sola Shale and the overlying Rodby Shale Member top-seal. The overall project was focussed on characterising the reservoir and the overlying top-seal but it must be noted that good-quality core through reservoir sections is not routinely collected and core through shales is rarely collected during conventional oil and gas exploration, appraisal and field development. We considered it be good fortune to find any cores that contained sealing shale lithologies. Cores through the Carrack Shale, locally sitting between the Captain sandstone and Rodby Shale, were not identified in our searches through composite logs in this area.

The Balmoral Field, operated by Premier Oil (Aberdeen, UK), was selected for the second part of this study as it is located within the planned East Mey CCS site. Two wells, 16/21a-13 and 16/21a-20 (Figure 1C), were high graded for detailed study since they had core that was collected from both the Mey Sandstone Member and the overlying Lista Shale top-seal. Cores through the Forties Shale, locally 
sitting on top of the Lista Formation, were not identified in our searches through composite logs in this area.

Wireline logs and core analysis data were provided by the oil companies that made the core available. When core analysis was originally undertaken to characterise the reservoir intervals, by the operators, porosity and permeability data were not collected from the mudstones of interest to this study, but some core in each of the four wells was collected for the present study through the mudstones allowing new laboratory analyses.

For the Lower Cretaceous Acorn site, core samples of both the storage domain sandstones and the top-seal mudstones were provided by the operator; cores were examined at the ALS core store in Guildford, UK, and whole metre-long sections of core were selected for further study based on initial examination of wireline log and core analysis data. Core samples of both the storage domain sandstones and the top-seal mudstones for the Palaeocene East Mey CCS site were provided by the operator; all available core material from wells 16/21a-13 in the Blair oil field and 16/21a-20 in the Balmoral oil field were couriered to the University of Liverpool where they were examined and samples selected for further study.

\subsection{Wireline Log Data}

All wells in the study had standard sets of downhole log data collected: calliper (CAL), gamma (GR), density (RHOB), compressional sonic (DTCO) and deep resistivity (RD) (Table 1). All logs were plotted using opensource Rstudio software (version 3.5.2), ggplot2 (version 3.3.0) [15]; the code developed to plot the logs is available upon request. All wells except 16/21-13 have neutron (NPHI) $\log$ data available. Only the Acorn site wells 14/26a-7A and 14/26a-8 had shear sonic (DTS) logs. The density and neutron log data are plotted on common depth diagrams with opposite scales on the $\mathrm{X}$-axes. These diagrams are typically used [16] for reservoir evaluation to show the crossover areas. Where density $\log$ sits to the left of the neutron log, then the interval is assumed to be relatively porous (net pay). Where the density log sits to the right of the neutron log, then the interval is assumed to have low porosity and is classed as non-net pay (non-reservoir).

For the overall interpretation of lithology and fluid saturation, porosity was derived from the density log using:

$$
\text { Porosity }\left(\phi_{\mathrm{RHOB}} \%\right)=100 \times \frac{\rho_{\mathrm{ma}}-\rho_{\mathrm{b}}}{\rho_{\mathrm{ma}}-\rho_{\mathrm{fl}}}
$$

where $\rho_{\mathrm{ma}}$ is the assumed matrix (rock) density, $\rho_{\mathrm{b}}$ is the measured bulk rock density (RHOB) and $\rho_{\mathrm{fl}}$ is the assumed fluid density for the invaded zone of the near well-bore region (approximately $1 \mathrm{~g} / \mathrm{cm}^{3}$ ). Values of $\rho_{\mathrm{b}}$ (matrix density) were slightly varied to optimise the fit of the reservoir section core analysis porosity to the derived density log porosity. The uncertainty in the log-derived porosity values is at least $\pm 1 \%$, but comparison of the core analysis to the log-derived porosity values (Figures 3-7) suggests that the log-derived porosity values from the shales are credible. 
Table 1. Summary of wireline log availability for the five wells used in this study. Abbreviations and units are also listed.

\begin{tabular}{|c|c|c|c|c|c|c|c|c|c|c|c|}
\hline \multirow{3}{*}{ CCS Site } & $\log$ & Caliper & $\begin{array}{l}\text { Spontaneous } \\
\text { Potential }\end{array}$ & Gamma & Density & $\begin{array}{l}\text { Near and Far } \\
\text { RHOB Detector } \\
\text { Difference }\end{array}$ & $\begin{array}{c}\text { Sonic- } \\
\text { Compressional }\end{array}$ & Sonic-Shear & Neutron & $\begin{array}{l}\text { Spectral } \\
\text { Gamma }\end{array}$ & $\begin{array}{c}\text { Deep } \\
\text { Resistivity }\end{array}$ \\
\hline & & CAL & SP & GR & RHOB & DRHO & DTCO & DTS & NPHI & SGR & RD \\
\hline & Units & Inches & $\mathrm{mV}$ & API Units & $\mathrm{g} / \mathrm{cm}^{3}$ & $\mathrm{~g} / \mathrm{cm}^{3}$ & $\mathrm{us} / \mathrm{ft}$ & us/ft & $\%$ & ppm or $\%$ & ohm.m \\
\hline \multirow{3}{*}{$\begin{array}{c}\text { Lower } \\
\text { Cretaceous } \\
\text { Acorn CCS site }\end{array}$} & $14 / 26-1$ & $\checkmark$ & $\checkmark$ & $\checkmark$ & $\checkmark$ & $\checkmark$ & $\checkmark$ & $x$ & $\checkmark$ & $x$ & $\checkmark$ \\
\hline & 14/26a-7A & $\checkmark$ & $\checkmark$ & $\checkmark$ & $\checkmark$ & $\checkmark$ & $\checkmark$ & $\checkmark$ & $\checkmark$ & $\checkmark$ & $\checkmark$ \\
\hline & $14 / 26 a-8$ & $\checkmark$ & $\checkmark$ & $\checkmark$ & $\checkmark$ & $x$ & $\checkmark$ & $\checkmark$ & $\checkmark$ & $\checkmark$ & $\checkmark$ \\
\hline \multirow{2}{*}{$\begin{array}{l}\text { Palaeocene East } \\
\text { Met CCS site }\end{array}$} & $16 / 21-13$ & $\checkmark$ & $x$ & $\checkmark$ & $\checkmark$ & $x$ & $\checkmark$ & $x$ & $x$ & $x$ & $\checkmark$ \\
\hline & $16 / 21-20$ & $\checkmark$ & $x$ & $\checkmark$ & $\checkmark$ & $\checkmark$ & $\checkmark$ & $\times$ & $\checkmark$ & $\checkmark$ & $\checkmark$ \\
\hline
\end{tabular}




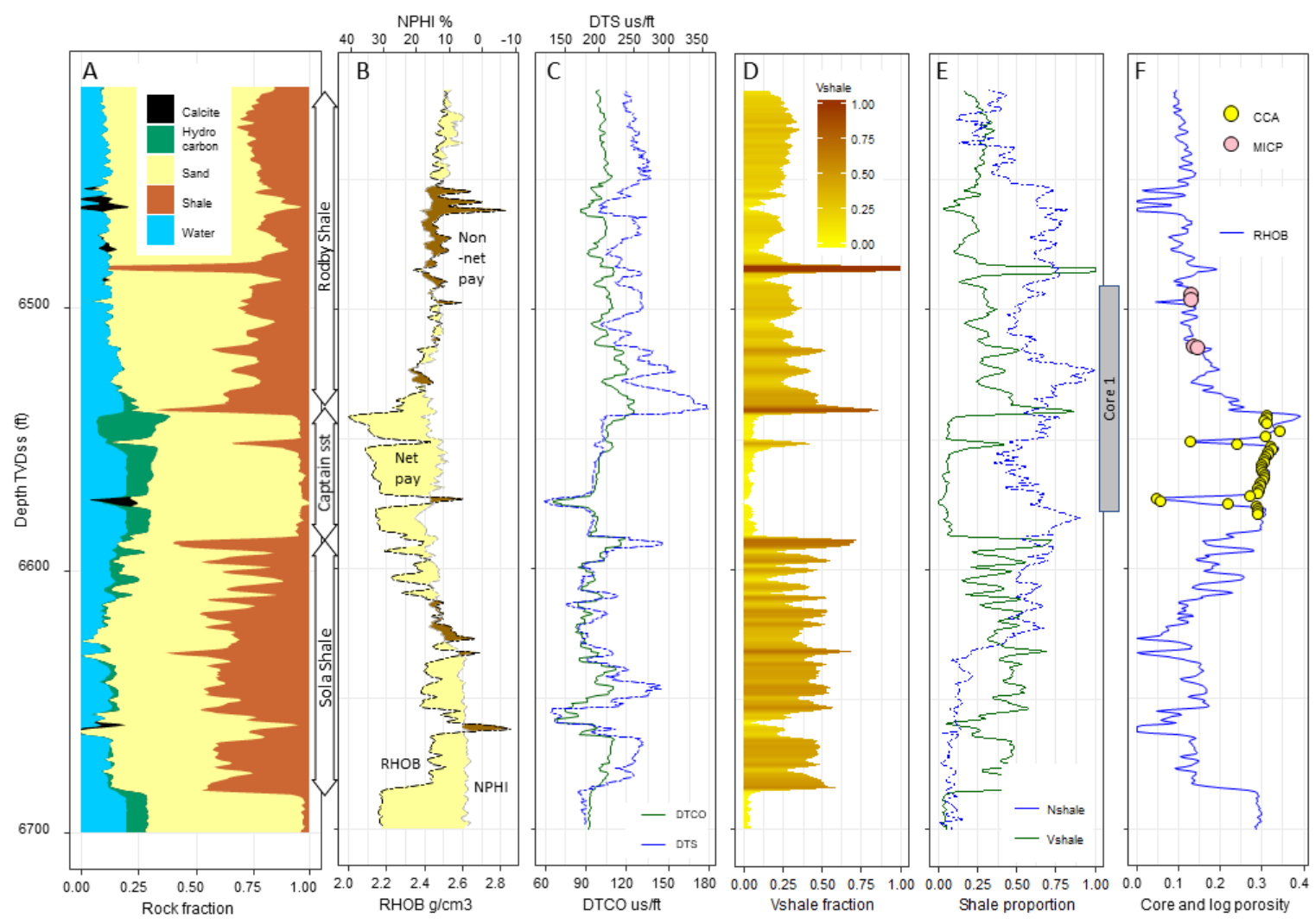

Figure 3. Wireline log raw and interpreted data from well 14/26a-7A from the Lower Cretaceous Acorn Storage Site. Diagrams (and in Figures 4-7) prepared using R-studio-ggplot2 software [15]. (A) Interpreted lithology and fluid saturation diagram showing the Sola Shale, overlain by the Captain Sandstone, which is overlain by the top-seal of the Rodby Shale. In this well, the Rodby Shale contains much non-shale material and has the lowest porosity in calcite-cemented layers (e.g., 6470-6480 ft). The pre-production petroleum column extended up to beneath the Rodby Shale. (B) Neutron-density crossover diagram confirming that the Rodby Shale has intermediate properties (largely non-net reservoir but crossover area remaining narrow). (C) Sonic log data; compressional sonic (DTCO) and the compressional shear log (DTS). The higher ratio of DTS to DTCO in the Rodby Shale, and mid Captain Sola Shale, than the cleaner sandstone reflects the lower Young's modulus in the shale than the sandstone. Note that calcite-cemented layers have the lowest DTS/DTCO ratio reflecting the locally high Young's modulus. (D) Vshale representation based on gamma ray logs. The highest Vshale sections equate to the weakest rocks (compare D to C). (E) Vshale compared to Nshale, where the latter is derived from the normalised difference between the neutron log and the density-derived porosity. Vshale represents the relative abundance of K-bearing clay minerals (and K-feldspar), whereas Nshale represents the sum total of all clay minerals (and any other H-bearing minerals). The high Nshale compared to Vshale in the Rodby Shale suggests that there is a relatively high abundance of non-radioactive clay minerals, such as kaolinite or chlorite. (F) Density log-derived porosity (RHOB) compared to core analysis (CCA)- and mercury intrusion (MICP)-derived porosity showing that the density $\log$ porosity values are accurate and that the Rodby Shale has porosity values of approximately $14 \%$. The very low porosity values in the Rodby Shale at approximately 6470-6480 ft are probably due to the presence of calcite cement (see A). 


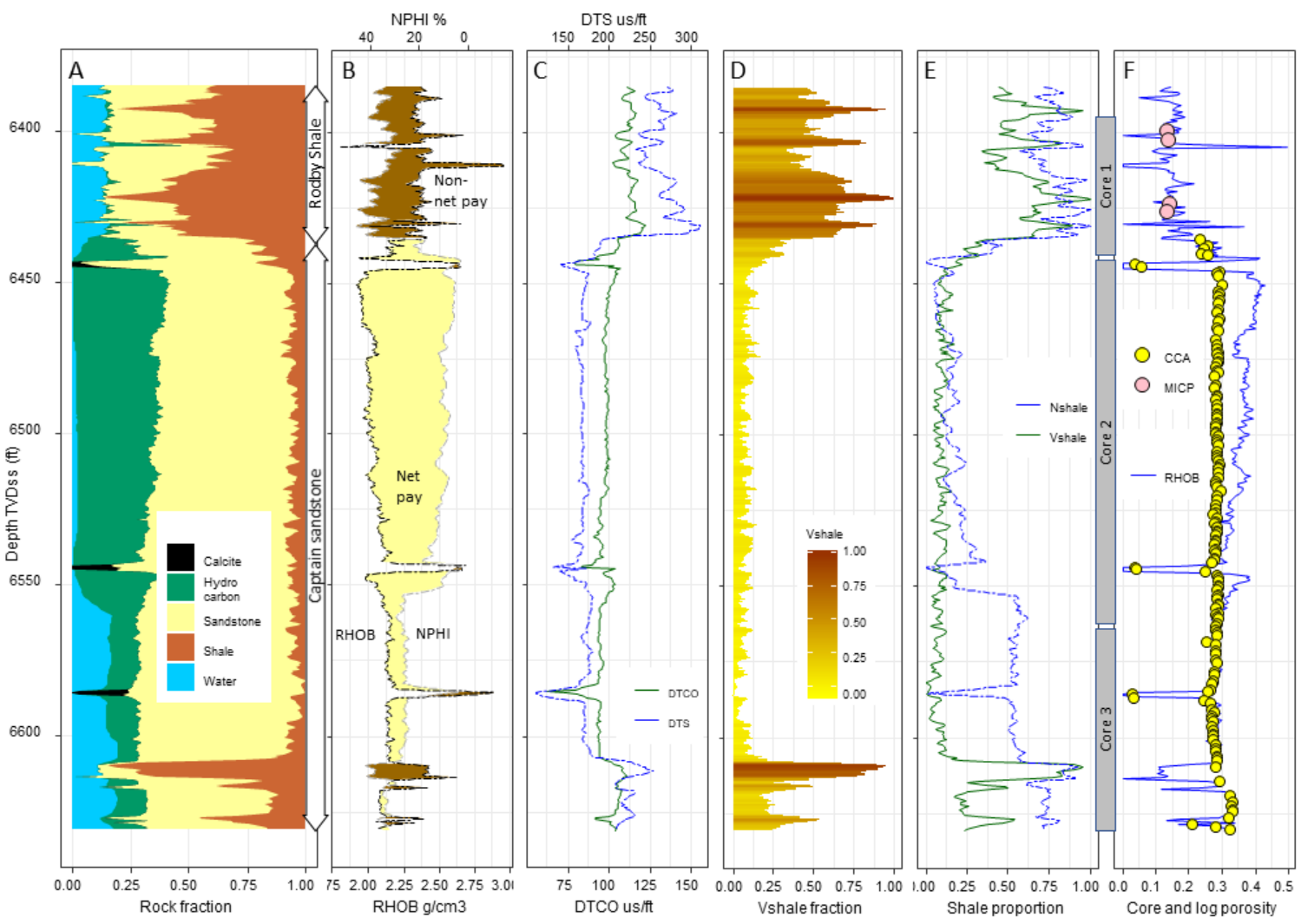

Figure 4. Wireline log raw and interpreted data from well 14/26a-8 from the Lower Cretaceous Acorn Storage Site. (A) Interpreted lithology and fluid saturation diagram showing the Captain Sandstone which is overlain by the top-seal of the Rodby Shale. In this well, the Rodby Shale seems to be very shale rich. The pre-production petroleum column extended up to beneath the Rodby Shale. The petroleum saturation seems to have been very high, suggesting that the top-seal was very effective. (B) Neutron-density crossover diagram confirming that the Rodby Shale is a good seal (non-net reservoir with extensive and wide crossover). (C) Sonic log data; compressional sonic (DTCO) and the compressional shear log (DTS). The higher ratio of DTS to DTCO in the Rodby Shale than the cleaner sandstone reflects the lower Young's modulus in the shale than the sandstone. (D) Vshale representation based on gamma ray logs. The highest Vshale sections equate to the weakest rocks (compare D to C). (E) Vshale compared to Nshale, where the latter is derived from the normalised difference between the neutron $\log$ and the density-derived porosity. Vshale represents the relative abundance of K-bearing clay minerals (and K-feldspar), whereas Nshale represents the sum total of all clay minerals (and any other H-bearing minerals). The slightly elevated Nshale compared to Vshale in the Rodby Shale suggests that there is a relatively high abundance of non-radioactive clay minerals, such as kaolinite or chlorite. (F) Density log-derived porosity (RHOB) compared to core analysis (CCA)- and mercury intrusion (MICP)-derived porosity showing that the density log porosity values are accurate and that the Rodby Shale has porosity values of approximately $14 \%$. The very low porosity values in the Rodby Shale at approximately 6400 and $6415 \mathrm{ft}$ are probably due to the presence of calcite cement. 


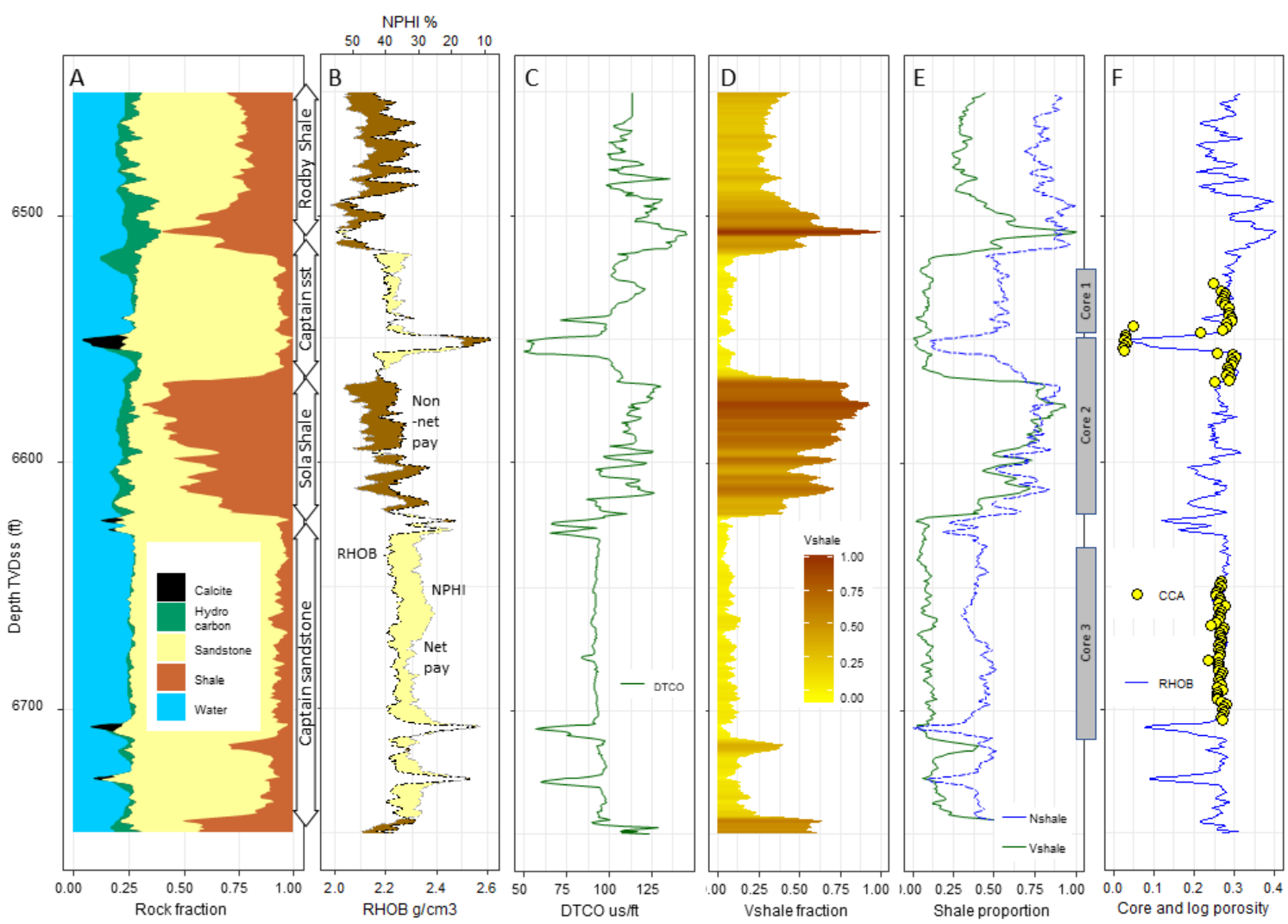

Figure 5. Wireline log raw and interpreted data from well 14/26-1 from the Lower Cretaceous Acorn Storage Site. (A) Interpreted lithology and fluid saturation diagram showing the Captain Sandstone, which is overlain by the Sola Shale baffle, which is overlain by the uppermost part of the Captain sandstone. The Rodby Shale was not cored in this well. (B) Neutron-density crossover diagram confirming that the Sola Shale is a good barrier or baffle (non-net reservoir with extensive crossover). (C) Sonic log data; only the compressional sonic (DTCO) log was run in this well, so there are no data on top-seal rock strength available. (D) Vshale representation based on gamma ray logs, revealing increasing shaliness up through the Sola Shale. (E) Vshale compared to Nshale, where the latter is derived from the normalised difference between the neutron log and the density-derived porosity. Vshale represents the relative abundance of K-bearing clay minerals (and K-feldspar), whereas Nshale represents the sum total of all clay minerals (and any other H-bearing minerals). The slightly elevated Nshale compared to Vshale in the Sola Shale suggests that there is a relatively high abundance of clay minerals, such as kaolinite or chlorite. The large difference between Nshale and Vshale in the sandier intervals suggests that the sandstones contain abundant kaolinite or chlorite (and little illite). (F) Density log-derived porosity (RHOB) compared to core analysis (CCA)-derived porosity showing that the density log porosity values are accurate. The Sola Shale has a relatively high porosity (mostly $>20 \%$ ), suggesting that this unit is a baffle rather than a barrier. 

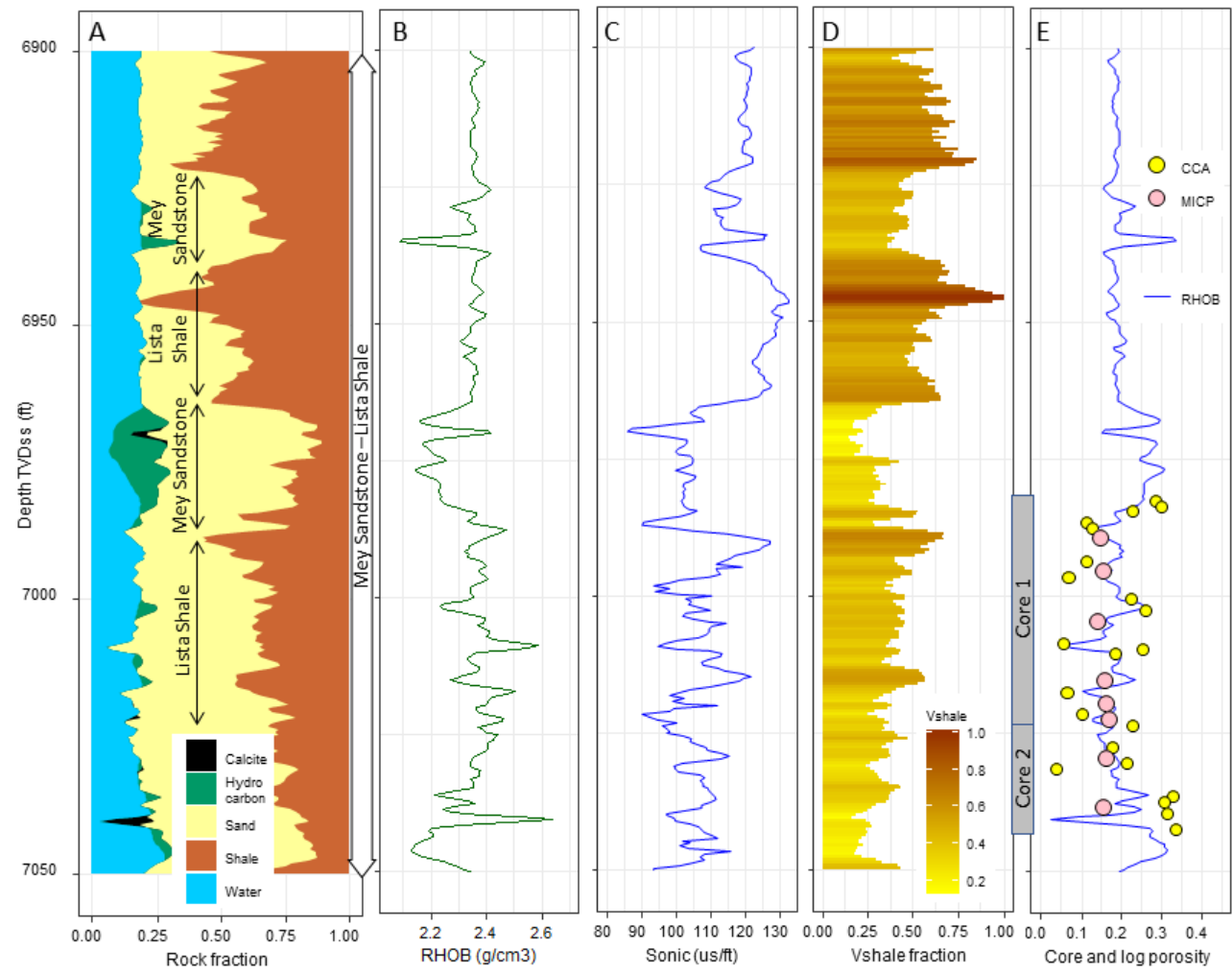

Figure 6. Wireline log raw and interpreted data from well 16/21a-13 from the Palaeocene East Mey Storage Site. (A) Interpreted lithology and fluid saturation diagram showing the Mey Sandstone and the interbedded Lista Shale baffle (i.e., intraformational shale). The most shaley part of the Lista was not cored in this well. (B) Density log; the neutron log was not run in this well, so a crossover diagram (e.g., Figure 3B) cannot be constructed. (C) Sonic log data; only the compressional sonic (DTCO) $\log$ was run in this well, so there are no data on top-seal rock strength available. (D) Vshale representation based on gamma ray logs revealing increasing shaliness up through the Soila Shale. (E) Density log-derived porosity (RHOB) compared to core analysis (CCA)- and mercury intrusion (MICP)-derived porosity showing that the density log porosity values are accurate. The shaley-part of the core has relatively high porosity (mostly $>16 \%$ ), suggesting that the shale in the cored unit is a baffle rather than a barrier. The upper part of this well has a higher Vshale (part D) but the porosity values remain at approximately $20 \%$.

The fluids in the pore space was divided into water and petroleum using the deep resistivity log and Equation (2), the Archie equation:

$$
S_{\mathrm{w}}=\sqrt[n]{\frac{\mathrm{a} \times \mathrm{R}_{\mathrm{w}}}{\phi_{\mathrm{RHOB}}^{\mathrm{m}} \times \mathrm{R}_{\mathrm{d}}}}
$$

where $S_{\mathrm{w}}$ is the fractional water saturation, a, $\mathrm{m}$ and $\mathrm{n}$ are the Archie constants (default values: 1, 2 and 2, but modified here to fit $S_{W}$ to as close to 1.00 as possible in the water leg), $\phi_{\mathrm{RHOB}}$ is the porosity determined using the density $\log$ (Equation (1)) and $R_{d}$ is the deep resistivity of the formation. Formation water resistivity values at the temperature of interest, $\mathrm{R}_{\mathrm{W}}$, were taken from Warren and Smalley [17].

The solid part of the rock was split into proportions of shale and sand using normalised gamma $\log$ data and the Vshale calculation:

$$
\text { Vshale }=1-\frac{\mathrm{GR}_{\mathrm{max}}-\mathrm{GR}_{\mathrm{b}}}{\mathrm{GR}_{\mathrm{ma}}-\mathrm{GR}_{\mathrm{fl}}}
$$


where $\mathrm{GR}_{\max }$ is the maximum gamma value for the reservoir top-seal section of interest, $\mathrm{GR}_{\mathrm{b}}$ is the measured gamma value for the depth of interest and $\mathrm{GR}_{\min }$ is the minimum gamma value for the reservoir top-seal section of interest. Vshale reveals the total quantity of radioactive minerals in the rock; this is often treated as being the same as the total quantity of clay minerals since these are often dominated by radioactive potassium-bearing illite (and mixed layer illite-smectite). Strictly speaking, Vshale therefore actually represents the quantity of illite and smectite (assuming the $\mathrm{GR}_{\min }$ value accounts for the quantity of radioactive potassium-bearing K-feldspar).

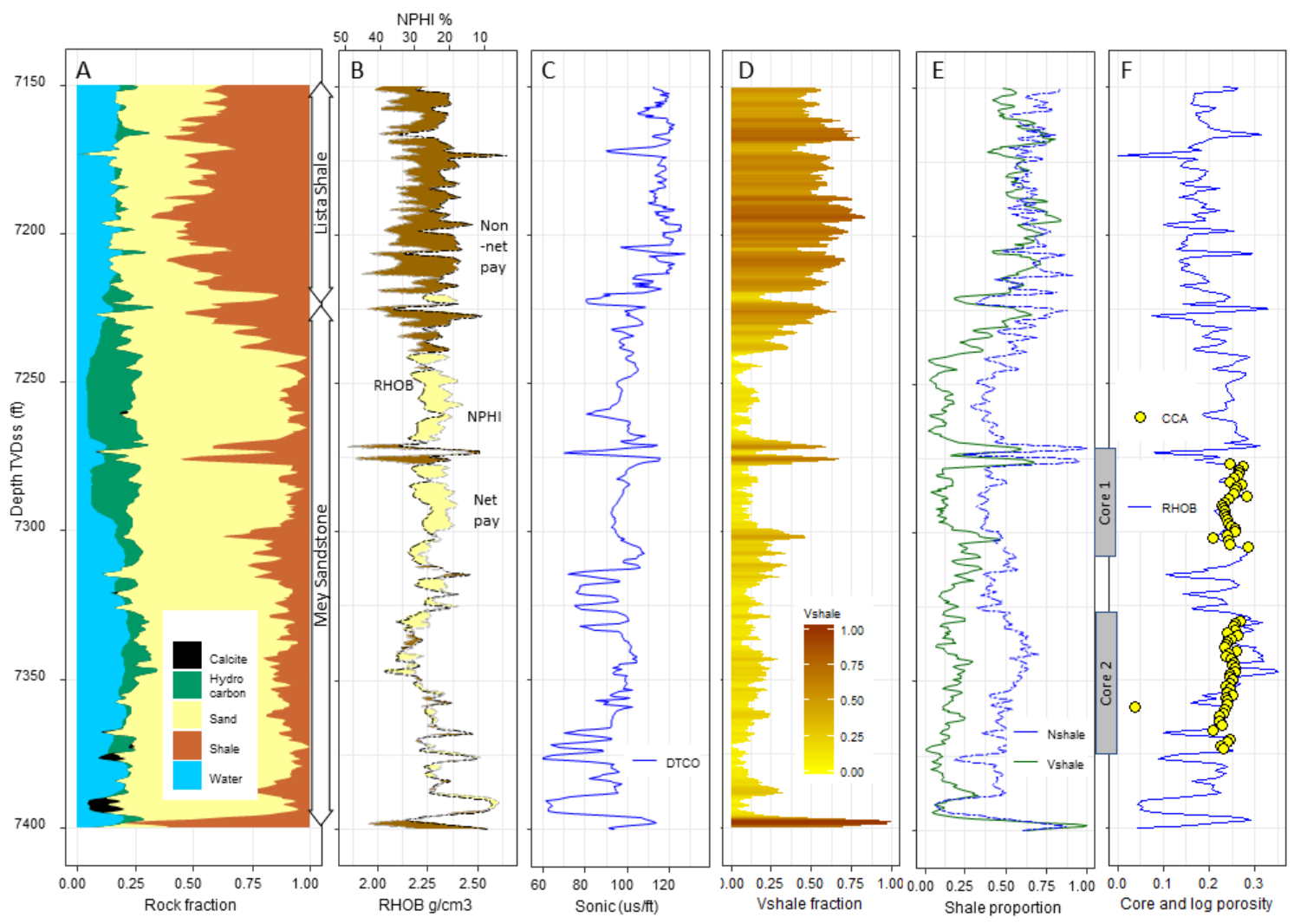

Figure 7. Wireline log raw and interpreted data from well 16/21-20 from the Palaeocene East Mey Storage Site. (A) Interpreted lithology and fluid saturation diagram showing the Mey Sandstone and Lista Shale top-seal. The most shaley part of the Lista was not cored in this well. (B) Neutron-density crossover diagram confirming that the Lista Shale has good top-seal properties (wide and stratigraphically extensive non-net reservoir). (C) Sonic log data; only the compressional sonic (DTCO) log was run in this well, so there are no data on top-seal rock strength available. (D) Vshale representation based on gamma ray logs. (E) Vshale compared to Nshale, where the latter is derived from the normalised difference between the neutron $\log$ and the density-derived porosity. Vshale represents the relative abundance of K-bearing clay minerals (and K-feldspar), whereas Nshale represents the sum total of all clay minerals (and any other H-bearing minerals). The roughly equivalent Nshale compared to Vshale in the Lista Shale suggests that there is a dominance of K-bearing radioactive clay minerals (e.g., illite and smectite) and relatively low abundance of non-radioactive clay minerals, such as kaolinite or chlorite. (F) Density log-derived porosity (RHOB) compared to core analysis (CCA)-derived porosity showing that the density log porosity values are largely very accurate and that the Lista Shale has porosity values mostly $>15 \%$. Mercury intrusion porosity measurements could not be made in this well as core was not collected through the true Lista Shale. The very low porosity value in the Lista Shale at approximately $7175 \mathrm{ft}$ is probably due to the presence of calcite cement.

The neutron log represents the total quantity of hydrogen in the rock, and thus includes pore fluids in the invaded near-well bore zone and hydroxyl-bearing clay minerals (and any other H-bearing mineral such as gypsum or zeolite). The absolute Nshale value (Nshale ${ }_{\text {abs }}$ ) can be derived by subtracting 
the percentage porosity, determined from the density log (Equation (1)), from the neutron, the result revealing the relative quantity of clay minerals:

$$
\text { Nshale }_{\text {abs }}=\mathrm{NPHI}(\%)-\phi_{\mathrm{RHOB}}
$$

where NPHI is the percentage neutron log signal and $\phi_{\mathrm{RHOB}}$ is the density log-derived porosity. The Nshale $\mathrm{abs}_{\text {abs }}$ values vary about zero. To normalise the data and make them comparable to Vshale values, we used:

$$
\text { Nshale }=1-\frac{\text { Nshale }_{\text {abs-max }}-\text { Nshale }_{\text {abs-b }}}{\text { Nshale }_{\text {abs-max }}-\text { Nshale }_{\text {abs-min }}}
$$

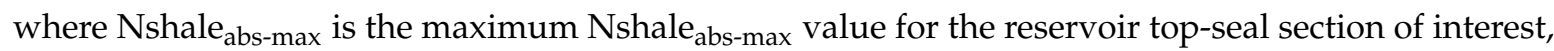
Nshale $_{\text {abs-b }}$ is the measured Nshale ${ }_{a b s}$ for the depth of interest and Nshale $e_{a b s-m i n}$ is the minimum Nshale $_{\text {abs }}$ value for the reservoir top-seal section of interest.

In principle, the difference between Vshale (radioactive clay minerals) and Nshale (all clay minerals) should reveal relative variations in the proportions of illite plus smectite versus the non-radioactive clay minerals such as kaolinite plus chlorite. High or increasing Nshale compared to Vshale suggests increasingly abundant kaolinite plus chlorite relative to illite plus smectite. Low or decreasing Nshale compared to Vshale suggests illite plus smectite-dominated shale.

\subsection{Petrography and Mineralogy}

Characterisation of the petrographic properties of the Rodby Shale and Lista Shale top-seals and Sola Shale intraformational baffle was primarily undertaken using automated Scanning Electron Microscopy-Energy Dispersive Spectroscopy (SEM-EDS). Polished thin sections were prepared in the standard manner for water-sensitive sections to a thickness of $30 \mu \mathrm{m}$ for rock samples that were first injected with blue dyed resin to highlight any porosity. These thin sections were then used for both optical microscope examination and SEM analysis.

Quantitative evaluation of mineral proportions was undertaken using automated SEM-EDS, which consists of an automated, spatially-resolved petrography system, based within a scanning electron microscope, using energy-dispersive $\mathrm{X}$-ray spectroscopy detectors and an extensive mineral database $[18,19]$. SEM-EDS analyses give quantitative mineral proportions, grain and pore space morphology and distribution to a minimum resolution of $\sim 1 \mu \mathrm{m}$ (the smallest beam-sample interaction volume width). SEM-EDS cannot identify or quantify microporosity and it cannot quantify any mineral grain that is smaller than approximately 1 or $2 \mu \mathrm{m}$. Monomineralic aggregates, e.g., of clay minerals, appear as one mineral grain and can be simply quantified. Mixtures of fine-grained minerals, e.g., clay-grade kaolinite and smectite, have the mixture assigned to the two minerals. The SEM-EDS instrument used in this study is an FEI WellSite QEMSCAN at the University of Liverpool, using a tungsten-filament, operating at $15 \mathrm{kV}$, equipped with two Bruker EDS detectors [20]. This technique allowed the microstructural and mineralogical characterisation of the Rodby Shale and Lista Shale top-seals and the intraformational Sola Shale.

X-ray diffraction (XRD) was also performed on several samples of the Rodby and Lista Shale samples to help ascertain fine-grained clay mineral type and proportions [21] and specifically to confirm the SEM-EDS determinations of mineralogy. Representative subsamples of the shale were crushed, in distilled water, to a powder $<10 \mu \mathrm{m}$ using an agate McCrone micronising mill and dried at $60{ }^{\circ} \mathrm{C}$. Dried samples were then crushed into a light and loose powder in an agate pestle and mortar and back-loaded into cavity holders as random powders. The samples were then saturated with ethylene glycol, by the vapour pressure method at $60^{\circ} \mathrm{C}$ for $24 \mathrm{~h}$ for accurate determination of the presence of swelling clay (smectite) and its composition. Samples were then scanned in a PANalytical X'Pert Pro MPD X-ray diffractometer. A copper X-ray tube was used, with a nickel filter to select for copper $k-\alpha$ radiation. Scans covered the range of 4 to $70^{\circ} 2 \theta$. Sample preparation, analysis and data quantification were all undertaken by the same individual using the same methods. Operation 
of XRD equipment and software was at the University of Liverpool, using the "HighScore Plus ${ }^{\circledR}$ " analysis software (Version 4.9, Malvern Panalytical, Malvern, UK), with quantification achieved using the Relative Intensity Ratio (RIR) method [22]. Reference patterns for the analysis were acquired from the International Centre for Diffraction Data, Powder Diffraction File-2 Release 2008.

\subsection{Mercury Intrusion Porosimetry}

The porosity and pore throat diameters of the Rodby and Lista Shales were determined using mercury injection porosimetry [23,24]. These analyses were performed by MCA Services (Cambridge, UK). Specimens were dried and vacuum outgassed at $60^{\circ} \mathrm{C}$ for $24 \mathrm{~h}$. Calculations of pore system properties were made assuming that the surface tension of mercury is $0.48 \mathrm{~N} / \mathrm{m}$ and that the contact angle between specimen surface and mercury is $141^{\circ}[25,26]$. No correction was made for effective stress at depth, so the porosity values from the mercury intrusion porosimetry may be elevated, possibly by $0.5 \%$ by reference to conventional reservoirs [27].

\subsection{Splitting Tensile Strength}

The indirect (Brazilian) tensile testing of rock cores was accomplished by applying diametric compressive stresses on two opposing curved surfaces of a rock disc [28]. This generated a uniform tensile stress on the plane containing the axis of the disc and the loaded surfaces, producing Mode I tensile fractures through the test specimen. The tests detailed in this study were conducted using an unconfined uniaxial press in a Brazilian test jig at room temperature and humidity and were undertaken according to ASTM D3967-16 (2016) standards.

The calculation of the splitting tensile strength of the test specimen was achieved through the following equation:

$$
\sigma_{\mathrm{t}}=\frac{1.272 \times \mathrm{P}}{\pi \times \mathrm{L} \times \mathrm{D}}
$$

where $\sigma_{t}$ is the splitting tensile strength (STS) in MegaPascal (MPa), $\mathrm{P}$ is the maximum force applied indicated by the load cell in Newtons $(\mathrm{N}), \mathrm{L}$ is the length of the specimen in millimetres $(\mathrm{mm})$ and $\mathrm{D}$ is the diameter of the specimen in millimetres $(\mathrm{mm})$ [28]. For a more detailed explanation of this technique, see Allen, et al. [29].

\section{Results}

In the following sections, the results from wireline log, mineralogical, petrographic, mercury intrusion porosimetry and geomechanical testing analyses will be presented. The data from these techniques are integrated and explained in the subsequent Interpretation and Synthesis section.

\subsection{Wireline Log and Conventional Core Analysis Data}

\subsubsection{Acorn: Lower Cretaceous Rodby and Sola Shales}

Full $\log$ suites were run for wells 14/26a-7A and 14/26a-8 (Table 1). For 14/26a-7A, the synthesis of the density-derived porosity (Equation (1)), the Archie-derived fluid saturation (Equation (2)) and the Vshale-derived split between sand and shale (Equation (3)) is represented in Figure 3A. This figure also represents calcite-cemented sandstones where the interval is relatively shale free and yet the porosity is close to zero. Calcite-cemented sandstones have the lowest porosity in the whole section. The Captain Sandstone Member contains increasing quantities of petroleum below the Rodby Shale top-seal. According to their intermediate Vshale values, the Rodby Shale and the intraformational Sola Shale appear to be relatively "sand" rich, apart from two thin layers that seem to be shale rich (high Vshale values). The density-neutron crossover diagram (Figure 3B) confirms the presence of reservoir in the Captain Sandstone and also confirms the sand-rich nature of the Rodby and Sola Shales (noting that some of the Rodby and the Sola appear to be net pay - the part of the storage domain that will flow petroleum-in terms of crossover, and yet contains no petroleum according to the Archie-derived fluid 
saturation in Figure 3A). The shear and compressional sonic logs (co-plotted with different $\mathrm{X}$-scales in Figure 3C) mimic each other in the sandy sections but separate in the shalier section, particularly in the Rodby Shale; this reflects the lower Young's Modulus of the shales compared to the sands (Equations (7)-(9); see later). The Vshale, represented by intensity of colour in Figure 3D, confirms that the Rodby and Sola Shales are relatively sand rich but contain thin zones that are extremely shale rich. Comparison of Vshale and Nshale (Figure 3E), where Nshale is the result of the normalised difference between the neutron (\%) and density log-derived percentage porosity (Equations (1), (4) and (5)) suggests that the Rodby Shale (and perhaps the upper part of the Sola Shale) contains much clay material that is not illite or smectite and thus is relatively rich in kaolinite and chlorite. The Captain Sandstones also appear to be enriched in non-illite or -smectite clay minerals. For well 14/26a-7A, core was taken through the lower part of the Rodby Shale and the whole of the upper part of the Captain Sandstone (but not in the Sola Shale). During standard reservoir evaluation by the operator, conventional core analysis data (porosity and permeability) were produced for the Captain Sandstone but not for the Rodby Shale. The density log-derived porosity match excellently with the sandstone core porosity values (Figure 3F, Equation (1)). The density log-derived porosity for the Rodby and Sola Shales suggest that they have porosity between 10 and $15 \%$, with the lowest porosity occurring where the Vshale values are lowest, suggesting the presence of calcite-cemented layers or nodules.

The logs have been interpreted in the same way for well 14/26a-8 (Figure 4) as 14/26a-7A (Figure 3). The synthesis of the density-derived porosity, the Archie-derived fluid saturation and the Vshale-derived split between sand and shale is represented in Figure 4A. Calcite-cemented sandstones have the lowest porosity in the whole section. The Captain Sandstone Member has a high petroleum saturation below the Rodby Shale top-seal. The Rodby Shale has a thick section that is shale rich immediately above the reservoir. The density-neutron crossover diagram (Figure 4B) confirms the presence of an excellent reservoir in the Captain Sandstone and confirms the thick section of non-net pay in the Rodby Shale. The shear and compressional sonic logs have opposite relationships in the sand and the shale reflecting the lower Young's Modulus of the shales compared to the sands. The Vshale diagram (Figure 4D) confirms that the Rodby Shale is relatively sand poor and the Captain Sandstone is very clean (compare Figure 4B,D). Comparison of Vshale and Nshale (Figure 4E) suggests that the Rodby Shale contains much clay material that is not illite or smectite and thus is relatively rich in kaolinite and chlorite. The Captain Sandstone also appears to be enriched in non-illite or -smectite clay minerals. The lower part of the Captain Sandstone contains a sudden change in the Nshale (Vshale remains constant), suggesting that the lower sandstone is rich in kaolinite or chlorite compared to the clay-free upper part. For well 14/26a-8, core was taken through the lower part of the Rodby Shale and the whole of the upper part of the Captain Sandstone. During standard reservoir evaluation by the operator, conventional core analysis data (porosity and permeability) were produced for the Captain Sandstone but not the Rodby Shale. The density log-derived porosity largely match with the sandstone core porosity values (Figure $4 \mathrm{~F}$ ) although there is increasing deviation towards the top of the reservoir (suggesting a possible presence of gas). The density log-derived porosity for the Rodby Shale suggests that it has a porosity between 10 and $15 \%$, with the lowest porosity occurring where the Vshale values are lowest, which suggests the presence of calcite-cemented layers or nodules. Some of the high porosity values from the Rodby Shale may be an artefact of borehole conditions (caved borehole due to weak formation resulting in anomalous RHOB measurements).

The logs have been interpreted in the same way for well 14/26-1 (Figure 5) as the previous Acorn wells (Figures 3 and 4). The synthesis of the density-derived porosity, the Archie-derived fluid saturation and the Vshale-derived split between sand and shale is represented in Figure 5A. Calcite-cemented sandstone have the lowest porosity in the whole section. This well contains the Captain Sandstone, intraformational Sola Shale and the Rodby Shale top-seal. The Captain Sandstone Member has a relatively low petroleum saturation. The Rodby Shale has a thin interval above the reservoir that is shale rich. The Sola Shale appears to be sand poor in this well. The density-neutron crossover diagram (Figure 5B) confirms the presence of reservoir in the Captain Sandstone and confirms 
the presence of non-net pay in the Rodby and Sola Shales. A shear sonic log was not taken for this well (Figure 5C). The Vshale diagram (Figure 5D) confirms that the Rodby Shale is shale rich at its base but relatively sand rich in upper sections; the Sola Shale seems to be overall more shale rich than that Rodby Shale. Comparison of Vshale and Nshale (Figure 5E) suggests that the Rodby Shale contains much clay material that is not illite or smectite and thus is relatively rich in kaolinite and chlorite. The Captain Sandstone also appears to be enriched in non-illite or -smectite clay minerals. For well 14/26-1, core was taken through the lower and upper Captain Sandstones and through part of the intraformational Sola Shale. During standard reservoir evaluation by the operator, conventional core analysis data (porosity and permeability) were produced for the Captain Sandstone but not the Sola Shale. The density log-derived porosity largely match with the sandstone core porosity values (Figure 5F). The density log-derived porosity for the Rodby and Sola Shales suggest that they have porosity of approximately $20 \%$ compared to approaching 30\% porosity in the sandstones. Some of the highest porosity values from the Rodby and Sola Shales may be an artefact of borehole conditions.

\subsubsection{East Mey: Palaeocene Lista Shales}

The wells studied from the East Mey site did not have full log suites run (Table 1).

The logs available have been interpreted in the same way for well 16/21-13 (Figure 6) as for the Acorn wells (Figures 3-5). The synthesis of the density-derived porosity, the Archie-derived fluid saturation and the Vshale-derived split between sand and shale is represented in Figure 6A. This well contains Lista Formation Shale and Mey Sandstone Member in the middle of the logged section where there is a small petroleum column below. The Mey Sandstone Member is relatively shale rich and has a relatively low petroleum saturation at approximately $6970 \mathrm{ft}$. A neutron log was not run so a density-neutron crossover diagram cannot be produced (Figure 6B). A shear sonic log was not taken for this well (Figure 6C). The Vshale diagram (Figure 6D) confirms that the Lista Formation is shale rich at some intervals. Core was collected from the lower part of the section. During standard reservoir evaluation by the operator, conventional core analysis data (porosity and permeability) were produced for the Lista Formation sandstones (the Mey Sandstone). The density log-derived porosity shows great fluctuation in the reservoir interval probably indicating that the reservoir is relatively shaley and possibly locally calcite-cemented (Figure 6A,E). The density log-derived porosity for the Lista Shale suggests that it has porosity of approximately $15 \%$. Some of the highest porosity values from the Lista Shale may be an artefact of borehole conditions.

The logs have been interpreted in the same way for well 16/21-20 (Figure 7) as the previous Acorn and East Mey wells (Figures 3-6). The synthesis of the density-derived porosity, the Archie-derived fluid saturation and the Vshale-derived split between sand and shale is represented in Figure 7A. This well contains Mey Sandstones in the lower part of the section and the Lista Shale top-seal. The Mey Sandstone Member has a relatively high petroleum saturation. The Lista Shale has a thick interval above the reservoir that is shale rich. The density-neutron crossover diagram (Figure 7B) confirms the presence of shale-bearing reservoir in the Mey Sandstone and confirms the presence of non-net pay in the Lista Shale. A shear sonic log was not taken for this well (Figure 7C). The Vshale diagram (Figure 7D) confirms that the Lista Shale is shale rich. Comparison of Vshale and Nshale (Figure 7E) suggests that the Lista Shale is dominated by illite- and smectite-rich clay minerals and does not contain much kaolinite and chlorite. For well 16/21-20, core was taken through the Mey Sandstones but not the Lista Shale. During standard reservoir evaluation by the operator, conventional core analysis data (porosity and permeability) were produced for the Mey Sandstone. The density log-derived porosity largely match with the sandstone core porosity values (Figure 7F). The density log-derived porosity for the Lista Shale suggest that it has a porosity of between 15 and $20 \%$ compared to 25 and $30 \%$ porosity in the sandstones. 


\subsection{Mercury Intrusion Porosimetry}

Mercury intrusion porosimetry (MICP) was performed on eight samples of the Rodby Shale and eight samples from the Lista Formation. We have here displayed the results in terms of mean pore throat size in Figure 8 and listed the summary of the results in Table 2. Permeability was derived using the method published by Swanson [30].

Lower Cretaceous Rodby Shale pore size distribution data have an overall mean value of approximately $0.018 \mu \mathrm{m}(18 \mathrm{~nm})$ but with sample mean values ranging from 0.011 to $0.021 \mu \mathrm{m}$ (Figure 8; Table 2). The Palaeocene Lista Shale pore size distribution data have an overall mean value also of approximately $0.018 \mu \mathrm{m}(18 \mathrm{~nm})$ but with sample mean values ranging from 0.014 to $0.023 \mu \mathrm{m}$. The Rodby Shale has slightly smaller pore throats than the Lista Shale but the two are not hugely different in terms of pore throat sizes.

Porosity values for the two shales are also given in Table 2 and are presented in comparison to density log-derived porosity in Figures 3,4 and 6. The Rodby Shale has a mean porosity of 13 to $14 \%$. The Lista Shale has a slightly higher porosity of 14 to $17 \%$. The MICP-derived porosity values are very close to the density log-derived porosity values for both the Rodby and Lista Shale. This further supports the generally very good agreement between reservoir core analysis porosity and density log-derived porosity and suggests that density log-derived porosity values for the top-sealing lithologies have substantial credibility.

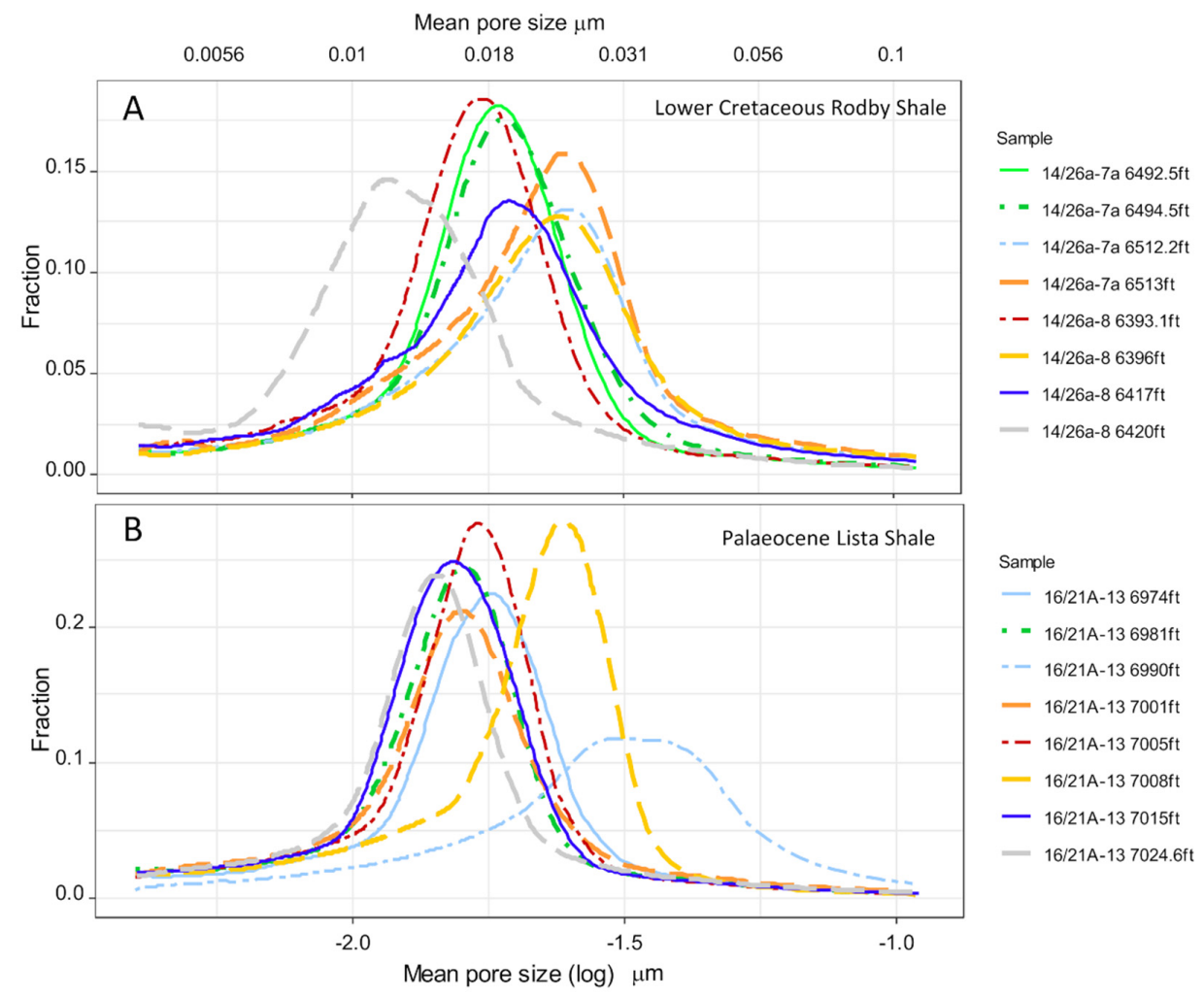

Figure 8. Comparison of the pore size distributions, from mercury intrusion porosimetry, from eight samples each in the Lower Cretaceous Rodby Shale and the finest grained parts of the Palaeocene Lista Formation. (A) Lower Cretaceous Rodby Shale pore size distribution data with an overall mean value of approximately $18 \mathrm{~nm}$ but with sample mean values ranging from 11 to $25 \mathrm{~nm}$. (B) Palaeocene Lista Shale pore size distribution data with an overall mean value of approximately $18 \mathrm{~nm}$ but with sample mean values ranging from $14 \mathrm{~nm}$ to approximately $31 \mathrm{~nm}$. The Rodby and Lista Shales are not hugely different in terms of pore throat sizes; if anything, the Rodby has slightly smaller pore throats than the Lista, at least as represented by these 16 samples. 
Table 2. Summary of results from mercury intrusion porosimetry from the Lower Cretaceous Rodby Shale and the Palaeocene Lista Shale. Permeability was derived using methods in Swanson [28]. Pore size distributions are presented graphically in Figure 8. Equation (7) was used to derive threshold pressure values for the brine- $\mathrm{CO}_{2}$ system based on the lab-derived mercury air with an assumed interfacial tension for brine- $\mathrm{CO}_{2}$ of $0.021 \mathrm{~N} / \mathrm{m}$. The derivation of the maximum $\mathrm{CO} 2$ column height was undertaken using Equation (8). Brine density was assumed to be $1.05 \mathrm{~g} / \mathrm{cm}^{3}$ for both Acorn and East Mey sites, based on regional data in Warren and Smalley [17]. $\mathrm{CO}_{2}$ density was assumed to be as $0.65 \mathrm{~g} / \mathrm{cm}^{3}$ based on Salem and Shedid [31]. The brine- $\mathrm{CO}_{2}$ contact angle was assumed to be 115 [24].

\begin{tabular}{|c|c|c|c|c|c|c|c|c|c|c|}
\hline Well & Depth (ft) & Lithology & $\begin{array}{c}\text { Mean Pore } \\
\text { Throat Size } \\
(\mathrm{mm})\end{array}$ & $\begin{array}{c}\text { Log of Mean } \\
\text { Pore Throat } \\
\text { Size (mm) }\end{array}$ & Porosity (\%) & Tortuosity & $\begin{array}{l}\text { Derived } \\
\text { Permeability } \\
(\mathrm{mD})\end{array}$ & $\begin{array}{l}\text { Hg-air Capillary } \\
\text { Entry Pressure } \\
\text { (psia) }\end{array}$ & $\begin{array}{c}\text { Max } \mathrm{CO}_{2} \\
\text { Column Height } \\
\text { (m) for } 115^{\circ} \text { b-c } \\
\text { Contact Angle }\end{array}$ & $\begin{array}{c}\mathrm{Max} \mathrm{CO}_{2} \\
\text { Column Height } \\
\text { (m) for } 110^{\circ} \mathrm{b}-\mathrm{c} \\
\text { Contact Angle }\end{array}$ \\
\hline 16/21a-13 & 6975.00 & Lista Shale & 0.0151 & -1.8210 & 15.01 & 3168 & 0.0002 & 10,044 & 395 & 320 \\
\hline 16/21a-13 & 6981.00 & Lista Shale & 0.0141 & -1.8517 & 15.72 & 1308 & 0.0002 & 11,409 & 449 & 363 \\
\hline 16/21a-13 & 6991.00 & Lista Shale & 0.0235 & -1.6284 & 14.15 & 2235 & 0.0006 & 4215 & 166 & 134 \\
\hline 16/21a-13 & 7001.00 & Lista Shale & 0.0146 & -1.8345 & 15.75 & 1431 & 0.0002 & 10,911 & 430 & 348 \\
\hline 16/21a-13 & 7005.00 & Lista Shale & 0.0147 & -1.8315 & 16.33 & 3974 & 0.0002 & 10,007 & 394 & 319 \\
\hline $16 / 21 a-13$ & 7008.00 & Lista Shale & 0.0175 & -1.7580 & 17.02 & 2806 & 0.0004 & 8012 & 315 & 255 \\
\hline 16/21a-13 & 7015.00 & Lista Shale & 0.0137 & -1.8639 & 16.25 & 3992 & 0.0002 & 11,968 & 471 & 381 \\
\hline 16/21a-13 & 7024.60 & Lista Shale & 0.0138 & -1.8608 & 15.45 & 876 & 0.0001 & 11,750 & 463 & 374 \\
\hline 14/26a-8 & 6393.10 & Rodby Shale & 0.0149 & -1.8256 & 13.43 & 2692 & 0.0002 & 11,418 & 450 & 364 \\
\hline $14 / 26 a-8$ & 6396.00 & Rodby Shale & 0.0209 & -1.6792 & 14.03 & 3289 & 0.0003 & 7669 & 302 & 244 \\
\hline $14 / 26 a-8$ & 6417.00 & Rodby Shale & 0.0180 & -1.7445 & 14.29 & 4530 & 0.0002 & 9166 & 361 & 292 \\
\hline $14 / 26 a-8$ & 6420.00 & Rodby Shale & 0.0114 & -1.9427 & 13.41 & 2174 & 0.0001 & 14,800 & 583 & 472 \\
\hline 14/26a-7A & 6492.50 & Rodby Shale & 0.0158 & -1.8002 & 13.15 & 2739 & 0.0002 & 10,666 & 420 & 340 \\
\hline 14/26a-7A & 6494.50 & Rodby Shale & 0.0168 & -1.7755 & 13.31 & 5430 & 0.0002 & 10,565 & 416 & 337 \\
\hline 14/26a-7A & 6512.20 & Rodby Shale & 0.0199 & -1.7014 & 13.70 & 2438 & 0.0003 & 7967 & 314 & 254 \\
\hline 14/26a-7A & 6513.00 & Rodby Shale & 0.0187 & -1.7286 & 14.67 & 3269 & 0.0003 & 8169 & 322 & 260 \\
\hline
\end{tabular}




\subsection{Core Description, Petrography and Mineralogy}

Mudstone core samples from both the Rodby and Lista Shales tend to be finely laminated (mm-scale) but also contain burrows at the scale of less than a millimetre up to $10 \mathrm{~mm}$ (Figure 9A,E). Cores are generally grey-brown and do not routinely split along fissile surfaces.
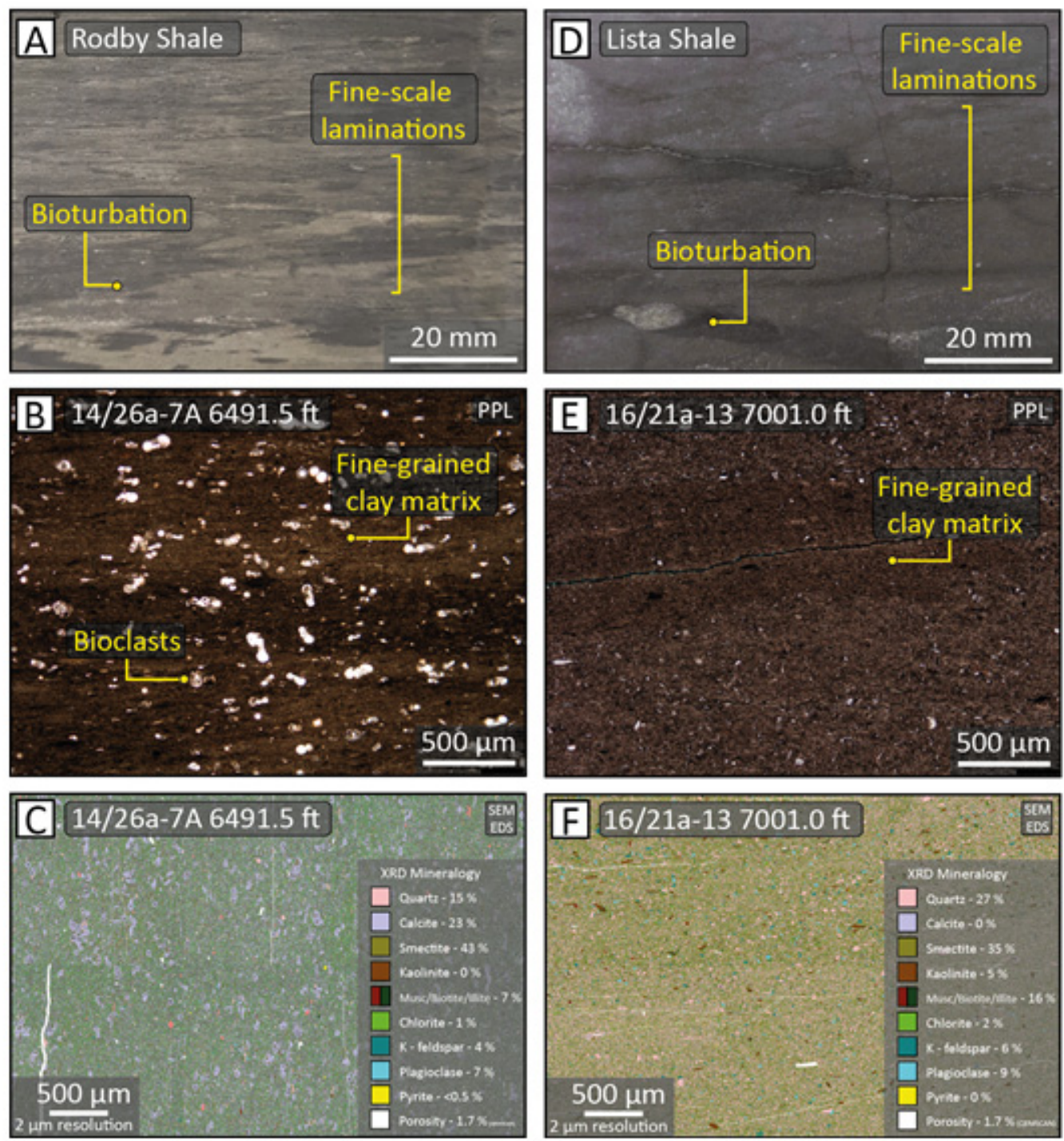

Figure 9. Core, thin section, and high-resolution SEM-EDS images of the Rodby and Lista Shales. (A) Fine-scale lamination and bioturbation in the Rodby Shale. The core proved to be highly sensitive to water, suggesting that the rock is rich in smectite. (B) Low-resolution light microscope image of the Rodby Shale revealing the dominant fine-grained matrix, silt grains and bioclasts. (C) High-resolution SEM-EDS image of a large area of the Rodby Shale, confirming the dominant fine-grained clay-rich (smectite), as well as quartz and calcite silt-sized material. (D) Fine-scale lamination and bioturbation in the Lista Shale. The core proved to be highly sensitive to water, suggesting that the rock is rich in smectite. (E) Low-resolution light microscope image of the Lista Shale revealing the dominant fine-grained matrix, with very small quantities of silt grains and bioclasts. (F) High-resolution SEM-EDS image of a large area of the Lista Shale confirming the dominant fine-grained clay-rich (smectite), with very small quantities of quartz and calcite silt-sized material.

Conventional thin sections of shales show little in optical light microscope, but they do give a sense of the residual bedding and reveal the presence of silty grains (Figure 9B,F). We did not get optically translucent $10 \mu \mathrm{m}$ thin sections made as the electron beam might have interacted with the glass slide 
in the SEM-EDS and corrupted the mineral analyses. Large area, medium resolution SEM-EDS images also reveal some degree of bedding and the dominance of clay minerals in most samples examined (Figure 9C,G). The Rodby Shale seems to contain variably abundant calcite, but the Lista Shale contains no calcite.

A series of high-resolution SEM-EDS images from the Rodby and Lista Shale samples illustrate the variation of grain size, clay mineralogy and the mineralogy of the silt-grade material in each suite of rocks. The Rodby Shale is dominated by smectite and calcite with variable quantities of kaolinite, quartz, and biotite (Figure 10). Calcite is present as microfossils in many samples, where the primary tests are intact and infilled with clay minerals (Figure 10B,C). Some Rodby Shale samples have abundant calcite present as 20 to $100 \mu \mathrm{m}$ structureless masses that may be pellets, cement, or a combination of both.
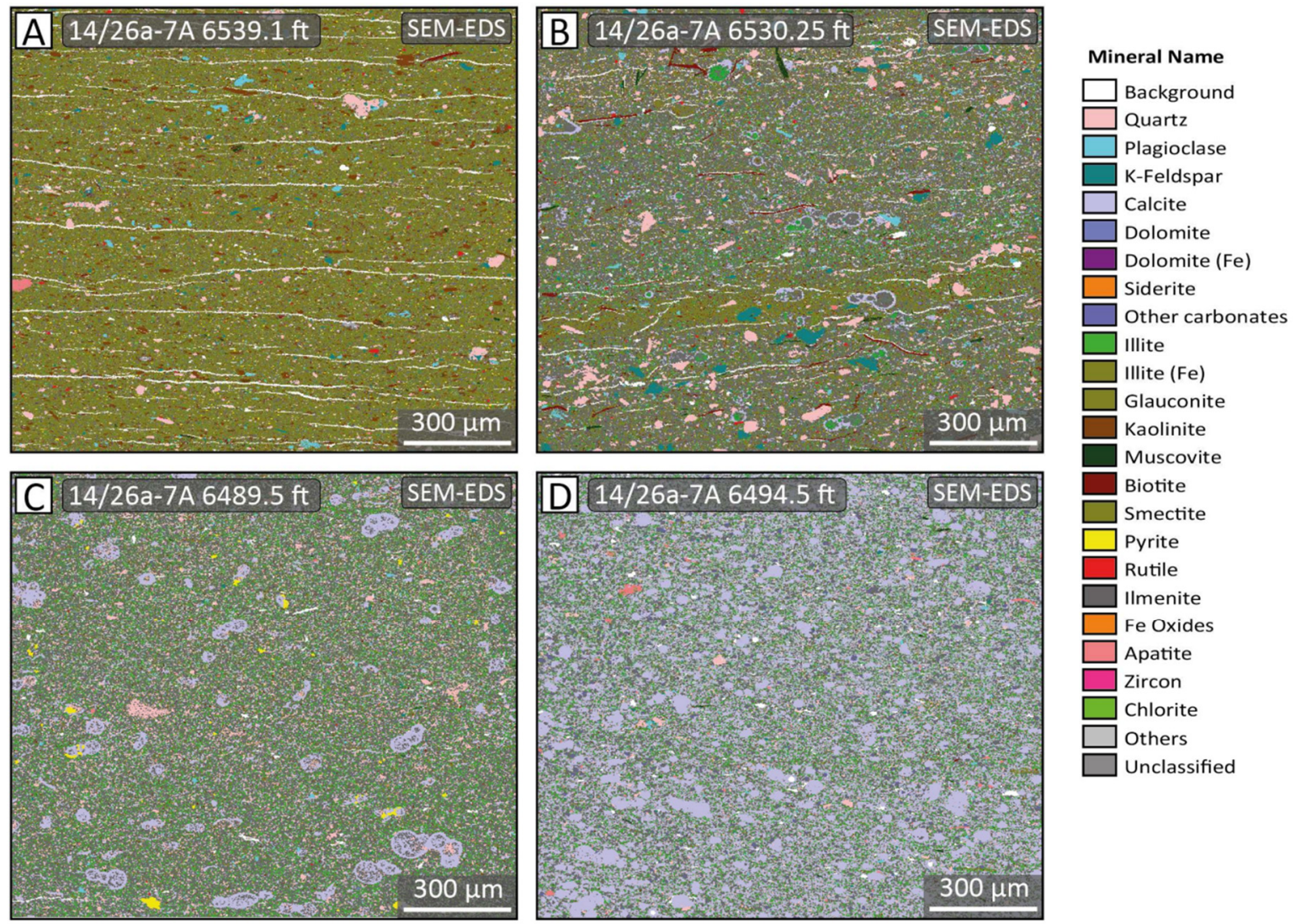

Figure 10. High-resolution SEM-EDS images of the Rodby Shale from well 14/26a-7A presented in order of increasing calcite concentration. These images reveal the mineralogy of samples but the pores in these shales are beyond the resolution of the SEM-EDS device (approximately 1 to $2 \mu \mathrm{m}$ minimum resolution). The key to relate the selected colours to mineral type is also shown. (A) Core depth $6539.1 \mathrm{ft}$ : smectite (77\%), kaolinite (11\%) and minor silt-grade quartz dominate this calcite-free sample. The cracks are artefacts of sample preparation but reveal the dominant shale parting orientation (B). Core depth $6530.25 \mathrm{ft}$ : smectite (57\%), quartz, $(12 \%)$ and calcite $(11 \%)$ dominate this sample but it also contains a significant quantity of detrital biotite $(12 \%)$. Calcite is partly present in the form of microfossils (C). Core depth $6489.5 \mathrm{ft}$ : smectite (50\%), quartz, $(22 \%)$ and calcite $(22 \%)$ dominate this sample. Calcite is present in the form of relatively abundant microfossils. (D). Core depth $6494.5 \mathrm{ft}$ : calcite-dominated sample (59\%), with some smectite (18\%) and other minerals. Calcite is present in some microfossils, but the majority is disseminated and recrystallised cement.

The Lista Shale is also dominated by smectite but, in comparison to the Rodby, contains no detectable calcite. Quartz is the dominant silt-grade mineral with minor to negligible quantities of 
kaolinite (Figure 11). Quartz is present as very fine silt $(4-10 \mu \mathrm{m})$ in some samples (Figure 11A-C) but can also be present as medium to coarse silt (Figure 11D).

XRD analyses, not illustrated here, confirmed that smectite is the dominant clay mineral. XRD also confirmed the abundance of calcite in the Rodby Shale and its absence in the Lista Shale.
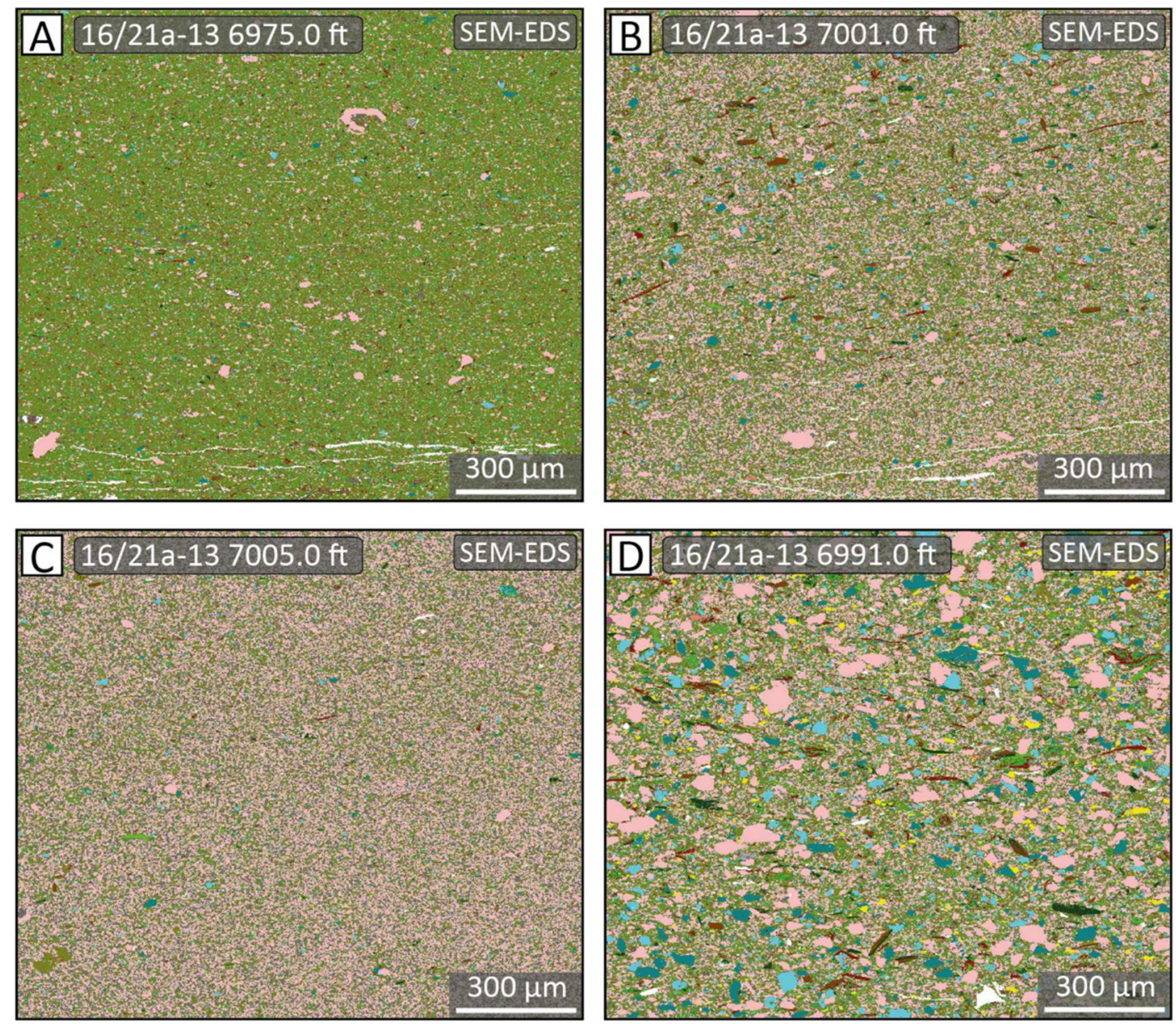

Figure 11. High-resolution SEM-EDS images of the Lista Shale in well 16/21a-13, presented in order of increasing quartz concentration. These images reveal the mineralogy of samples but the pores in these shales are beyond the resolution of the SEM-EDS device (approximately 1 to $2 \mu \mathrm{m}$ minimum resolution). The key to relate the selected colours to mineral type is shown in Figure 10. Calcite is absent in all samples. (A) Core depth $6975 \mathrm{ft}$ : smectite (83\%) and quartz (10\%), with quartz present as silt-sized grains (B). Core depth $7001 \mathrm{ft}$ : smectite (56\%), quartz, (34\%) dominate this sample with minor biotite. (C) Core depth $7005 \mathrm{ft}$ : fine quartz silt (63.9\%) dominates this sample with $30 \%$ smectite. (D) Core depth $6991 \mathrm{ft}$ : smectite (56\%) and coarse quartz silt (34\%) dominate this sample that is also rich in plagioclase (4.3\%) and K-feldspar (5.6\%) silt-grade material.

\subsection{Splitting Tensile Strength}

The splitting tensile strength (STS) values for the Rodby and Lista Shale samples are illustrated in Figure 12 with summary data presented in Table 3. The measurements were performed to characterise the anisotropy of the STS. With reference to the inset in Figure 12, samples were either horizontal (which was described as perpendicular to bedding by DeReuil, et al. [32]), or vertical or parallel to bedding (which were collectively described as parallel to bedding by DeReuil, Birgenheier and McLennan [32]). Measurements were carried out on dry samples. 
Table 3. Splitting tensile strength summary data from the Acorn and East Mey sites. In total, 42 measurements were made including repeats. The tests were made at different orientations with respect to bedding (see Figure 12): $\mathrm{H}$ is horizontal to bedding, P is parallel to bedding, and V is vertical to bedding. Overall, the horizontal samples represent the highest tensile strength (mean values of $\sim 2.5 \mathrm{GPa}$ ) of both the Lista and the Rodby Shales.

\begin{tabular}{|c|c|c|c|c|c|c|c|c|c|c|c|}
\hline Site & Well & Depth $(\mathrm{ft})$ & Lithology & Test Orientation & STS (MPa) & Site & Well & Depth $(\mathrm{ft})$ & Lithology & Test Orientation & STS (MPa) \\
\hline Acorn & $14 / 26 a-7 A$ & 6497.00 & Rodby & $\mathrm{H}-$ Horizontal & 2.76 & East Mey & 16/21a-13 & 6991.00 & Lista & H-Horizontal & 1.89 \\
\hline Acorn & $14 / 26 a-7 A$ & 6497.00 & Rodby & $\mathrm{H}-$ Horizontal & 2.52 & East Mey & 16/21a-13 & 6991.00 & Lista & $\mathrm{H}-$ Horizontal & 2.06 \\
\hline Acorn & $14 / 26 a-7 A$ & 6497.00 & Rodby & $\mathrm{H}-$ Horizontal & 1.15 & East Mey & 16/21a-13 & 6991.00 & Lista & H-Horizontal & 2.70 \\
\hline Acorn & $14 / 26 a-7 A$ & 6497.00 & Rodby & P-Parallel & 1.13 & East Mey & 16/21a-13 & 6991.00 & Lista & $\mathrm{H}-$ Horizontal & 2.11 \\
\hline Acorn & $14 / 26 a-7 A$ & 6497.00 & Rodby & P-Parallel & 1.31 & East Mey & 16/21a-13 & 6991.00 & Lista & $\mathrm{H}-$ Horizontal & 2.37 \\
\hline Acorn & $14 / 26 a-7 A$ & 6515.50 & Rodby & $\mathrm{H}-$ Horizontal & 2.75 & East Mey & 16/21a-13 & 6991.00 & Lista & H-Horizontal & 2.07 \\
\hline Acorn & 14/26a-7A & 6515.50 & Rodby & H-Horizontal & 1.55 & East Mey & 16/21a-13 & 6991.00 & Lista & $\mathrm{H}-$ Horizontal & 3.05 \\
\hline Acorn & $14 / 26 a-7 A$ & 6515.50 & Rodby & $\mathrm{H}-$ Horizontal & 3.07 & East Mey & 16/21a-13 & 6991.00 & Lista & $\mathrm{H}-$ Horizontal & 2.54 \\
\hline Acorn & $14 / 26 a-7 A$ & 6515.50 & Rodby & V-Vertical & 0.38 & East Mey & 16/21a-13 & 6991.00 & Lista & $\mathrm{H}-$ Horizontal & 2.20 \\
\hline Acorn & $14 / 26 a-8$ & 6402.50 & Rodby & $\mathrm{H}-$ Horizontal & 2.65 & East Mey & 16/21a-13 & 6991.00 & Lista & P-Parallel & 3.00 \\
\hline Acorn & $14 / 26 a-8$ & 6402.50 & Rodby & $\mathrm{H}-$ Horizontal & 2.35 & East Mey & $16 / 21 a-13$ & 6991.00 & Lista & P-Parallel & 2.00 \\
\hline Acorn & $14 / 26 a-8$ & 6402.50 & Rodby & $\mathrm{H}-$ Horizontal & 2.71 & East Mey & 16/21a-13 & 6991.00 & Lista & P-Parallel & 2.64 \\
\hline Acorn & $14 / 26 a-8$ & 6402.50 & Rodby & V-Vertical & 0.09 & East Mey & 16/21a-13 & 6991.00 & Lista & P-Parallel & 2.94 \\
\hline East Mey & $16 / 21 a-13$ & 6981.00 & Lista & $\mathrm{H}-$ Horizontal & 3.05 & East Mey & 16/21a-13 & 6991.00 & Lista & P-Parallel & 2.14 \\
\hline East Mey & $16 / 21 a-13$ & 6981.00 & Lista & $\mathrm{H}-$ Horizontal & 3.94 & East Mey & $16 / 21 a-13$ & 6991.00 & Lista & V-Vertical & 0.60 \\
\hline East Mey & $16 / 21 a-13$ & 6981.00 & Lista & V_-Vertical & 0.49 & East Mey & 16/21a-13 & 6991.00 & Lista & V-Vertical & 1.34 \\
\hline East Mey & $16 / 21 a-13$ & 6981.00 & Lista & P-Parallel & 1.37 & East Mey & 16/21a-13 & 6991.00 & Lista & V-Vertical & 0.80 \\
\hline East Mey & $16 / 21 a-13$ & 6981.00 & Lista & P-Parallel & 1.32 & East Mey & 16/21a-13 & 6991.00 & Lista & V-Vertical & 1.57 \\
\hline East Mey & $16 / 21 a-13$ & 6991.00 & Lista & $\mathrm{H}-$ Horizontal & 2.37 & East Mey & 16/21a-13 & 6991.00 & Lista & V-Vertical & 0.94 \\
\hline East Mey & $16 / 21 a-13$ & 6991.00 & Lista & H-Horizontal & 1.83 & East Mey & 16/21a-13 & 6991.00 & Lista & V_-Vertical & 1.29 \\
\hline East Mey & $16 / 21 a-13$ & 6991.00 & Lista & $\mathrm{H}-$ Horizontal & 1.94 & East Mey & 16/21a-13 & 7008.00 & Lista & $\mathrm{H}-$ Horizontal & 2.54 \\
\hline
\end{tabular}




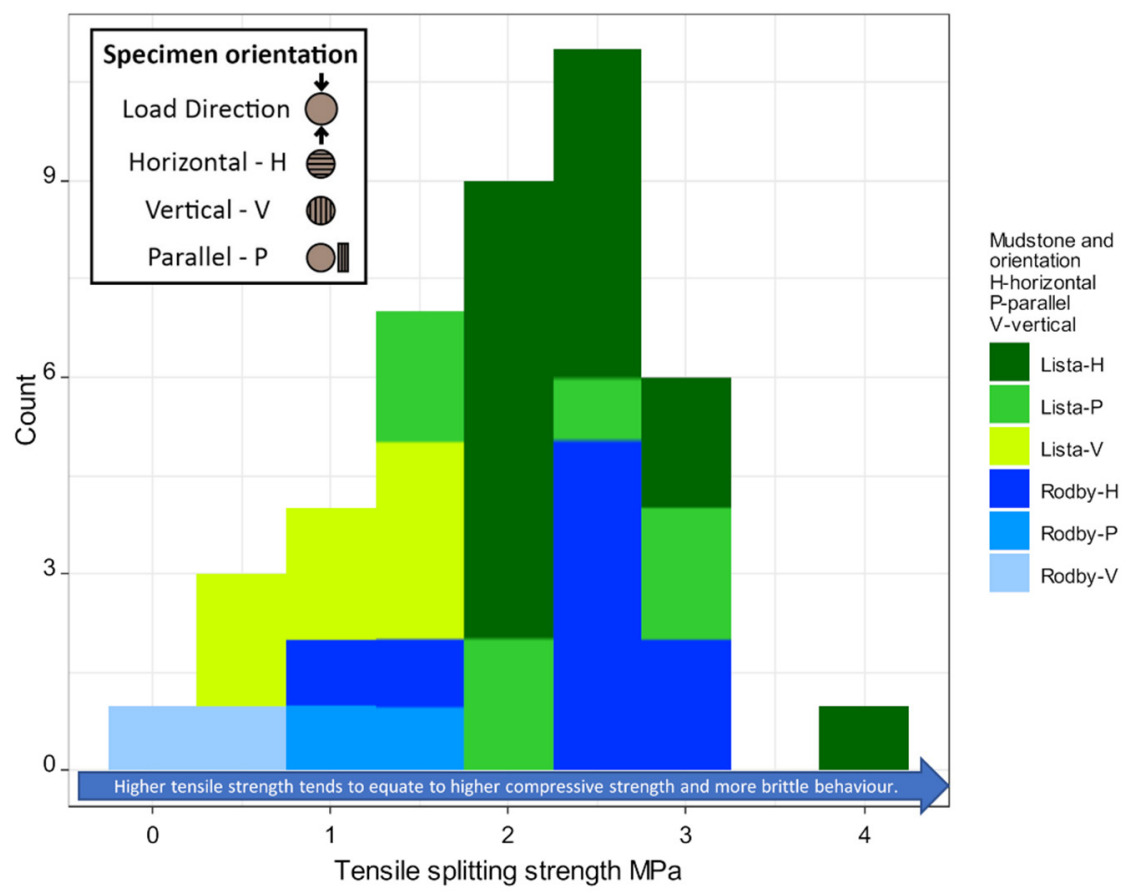

Figure 12. Comparison of tensile splitting strength data from 42 measurements- 13 from the Lower Cretaceous Rodby (blue tones) and 29 from the Palaeocene Lista (green tones). The tests were made at different orientations with respect to bedding (see inset), reflected in the colour intensity of the symbols (darkest: horizontal to bedding; medium: parallel to bedding; lightest: vertical to bedding). Overall, the horizontal samples represent the highest tensile strength (mean values of $\sim 2.5 \mathrm{GPa}$ ) of both the Lista and the Rodby Shales. In general, lower tensile strength tends to equate to higher compressive strength and more brittle behaviour, and vice versa.

The samples with the highest STS values tended to be horizontal sample and the vertical samples tended to have the lowest STS values (Figure 12). The Rodby and Lista Shale samples have broadly similar STS values despite the differences in porosity (Figures 3-7; Table 2) and mineralogy (Figures 10 and 11). There is no systematic variation of STS value with depth or proximity to reservoir in either the Rodby or Lista Shales.

\section{Interpretation and Comparison of Data Types}

\subsection{Comparison of Wireline Log Characteristics of the Rodby and Lista Shales}

It is not easy to gain an appreciation of the similarities and differences between the Lista and Rodby Shales simply by examining the collections of interpreted logs for each (Figures 3-7). It is easier to directly understand nuances of the wireline log data by comparing these on the same diagrams.

We have contrasted the gamma log data (GR) and the neutron log data (NPHI) for the Lista and the Rodby Shales in Figure 13. Both GR and NPHI respond to the presence of clay minerals; GR increases when the quantity of radioactive minerals such as illite and smectite increase. NPHI increases when the quantity of all clay minerals increases. Note that chlorite and kaolinite tend to increase the NPHI response more than illite since they have more hydroxyls $(-\mathrm{OH})$ per unit cell. The data have been further subdivided by the density (RHOB) log response and by the compressional sonic (DTCO) log response based on symbol size and colour. 


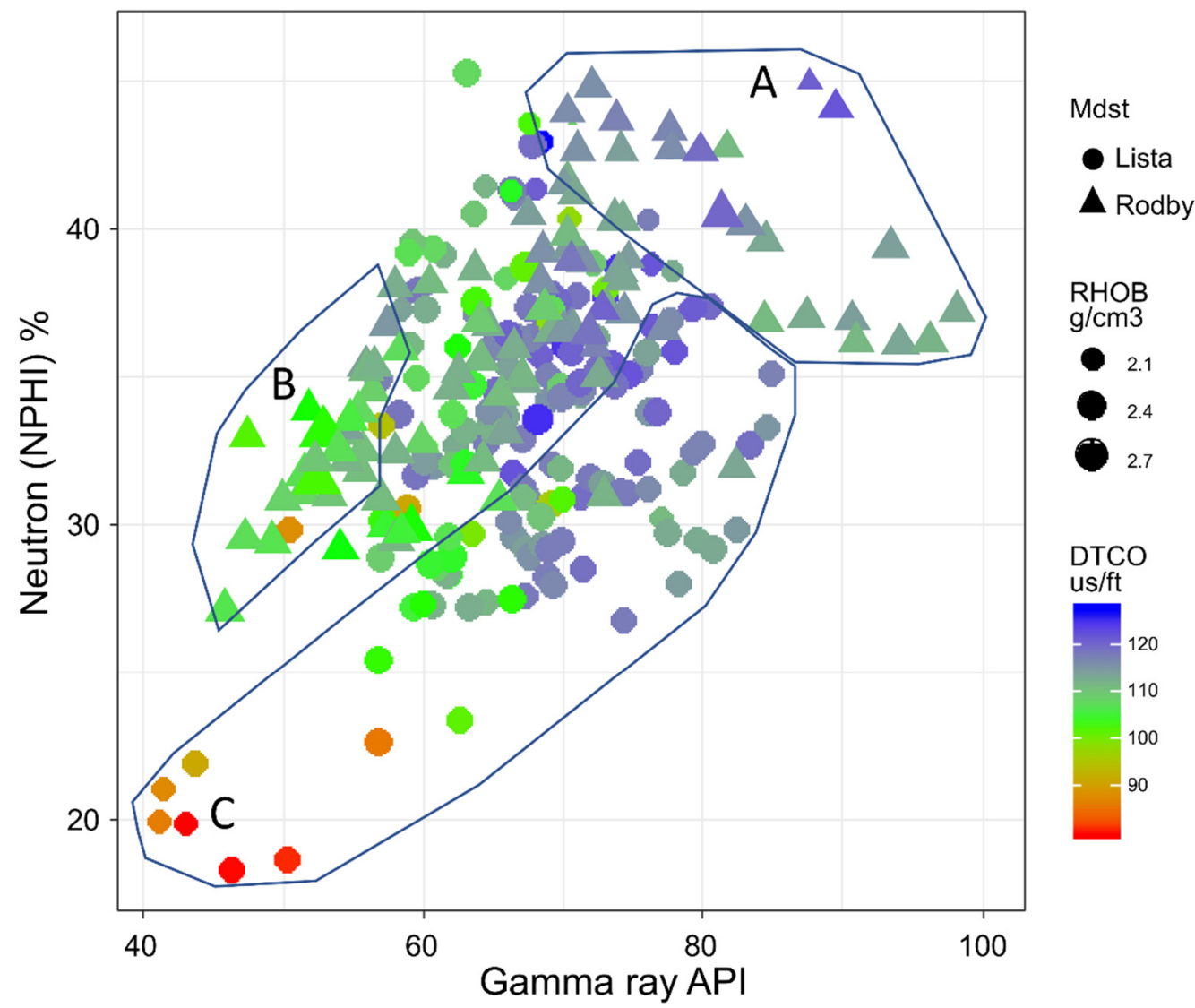

Figure 13. Comparison of the gamma and neutron log data between the Palaeocene Lista Shale (16/21-13 and 16/21-20; Figures 6 and 7) and the Lower Cretaceous Rodby Shale (14/26-1, 14/26a-7A and 14/26a-8; Figures 3-5), with the data characterised by the density log (RHOB, related to symbol size) and compressional sonic (DTCO related to colour in the rainbow spectrum) log values. Diagram prepared using R-studio-ggplot2 software [15]. High gamma is usually related to high shale content, but it actually reflects the quantity of radioactive minerals such as Illite, smectite and K-feldspar. High neutron reflects a combination of the porosity and quantity of clay (and other H-beating) minerals. High bulk density reflects decreasing porosity and increasing quantities of high-density minerals such as calcite. High sonic reflects increasing porosity and is also sensitive to rock mineral composition. There is clear overlap in the two datasets in the middle part of the graph. However, the Rodby extends into higher neutron and higher gamma values (area A) and relatively high neutron-low gamma values (area B), while the Lista extends from medium gamma and low neutron areas into relatively low neutron-high gamma values (area C). Area A represents illite-dominated shale, suggesting that the Rodby contains some layers of relatively silt- and sand-free mudstone. Area B represents shale with relatively low illite content. The medium- to high-sonic values suggest that these layers are shale, so the relatively low gamma suggests that these shales must be relatively rich in non-radioactive clay minerals such as kaolinite or chlorite. The lowermost part of area $\mathrm{C}$ probably represents sandstone layers. The higher values in area $C$ have high gamma for a given neutron value and represent smectite-rich shales with relatively low concentrations of non-radioactive clay minerals such as kaolinite or chlorite.

The symbol sizes are broadly similar, suggesting that the bulk density values of the two shales are similar. This can be explained by reference to Table 2 and in which the porosity of the Lista and the Rodby Shales is seen to vary little, between 13 and 17\% (and see Equation (1)). Bulk density is also a function of mineralogy but the mineralogy of the two formations is also not especially different except that the Rodby tends to be rich in relatively higher-density calcite. This small possible difference in average mineral density is not apparent in Figure 14. 

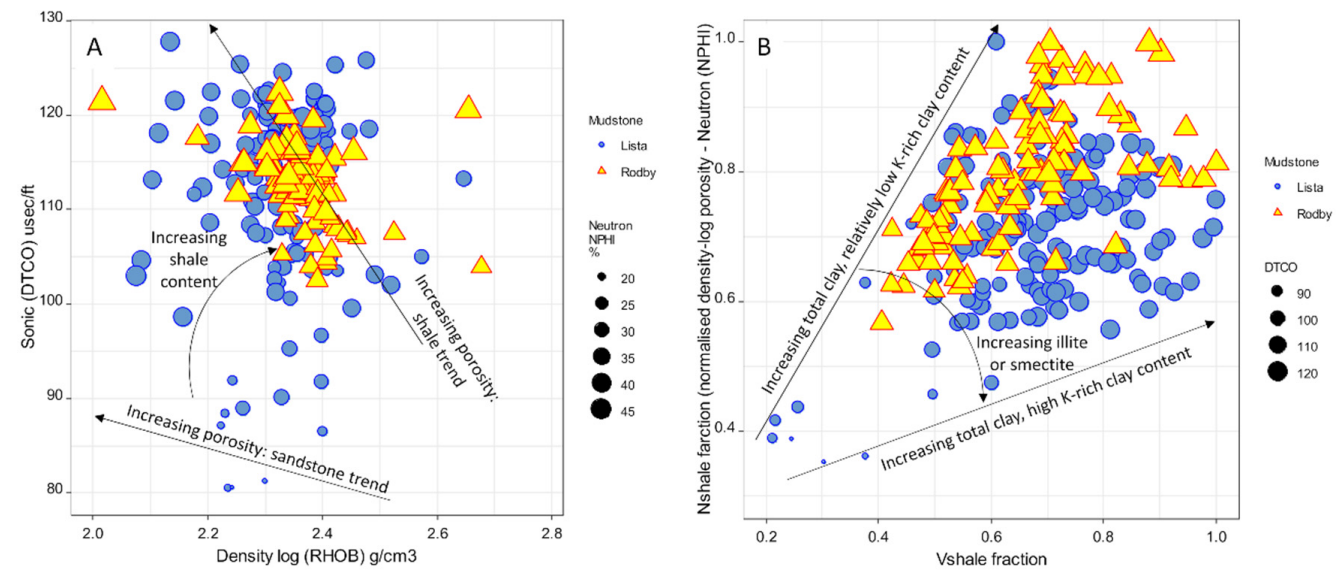

Figure 14. Comparison of raw and interpreted log properties for the Palaeocene Lista Shale (16/21-13 and 16/21-20; Figures 6 and 7) and the Lower Cretaceous Rodby Shale (14/26-1, 14/26a-7A and 14/26a-8; Figures 3-5). Diagrams prepared using R-studio-ggplot2 software [15]. (A) Density log (RHOB) and compressional sonic (DTCO) velocity with data graded by neutron (NPHI) response (represented by the sizes of the symbols). Typical trends of increasing porosity (for both sandstones and shales) and increasing clay mineral content are shown. The Rodby Shale tends to form a tighter cluster than the Lista Shale, suggesting a more homogeneous rock unit. (B) Vshale (normalised data based on gamma ray log maximum and minimum values in the entire sections for each shale in each well) and Nshale (derived from the normalised difference between the neutron log and the density-derived porosity) with data graded by sonic (DTCO) response (represented by the sizes of the symbols). Vshale represents the relative abundance of K-bearing clay minerals (and K-feldspar), whereas Nshale represents the sum total of all clay minerals (and any other H-bearing minerals). The Lista Shale tends to have a higher Vshale for a given Nshale than the Rodby Shale, suggesting that it is more smectite or illite rich; by default, the wireline log data suggest that the Rodby Shale must be richer in kaolinite, and maybe chlorite, than the Lista Shale.

In Figure 13, the symbol colours show a gradation from low DTCO (sonic) values in the lower left to the highest DTCO values to the upper right. The only difference between the Lista and Rodby is that the only rock intervals with DTCO values below $90 \mathrm{us} / \mathrm{ft}$ are from the Lista; these also have low GR and NPHI and probably represent sandstone beds. The Rodby Shale occupies the part of the diagrams with the highest NPHI and GR values (marked as area A on Figure 13). Area A represents smectite- or illite-dominated shale, suggesting that the Rodby contains some layers of relatively siltand sand-free mudstone. The Rodby Shale also occupies a part of the diagram with higher NPHI values for intermediate GR (area B on Figure 13). Area B probably represents shale with relatively low smectite or illite content. The medium- to high-sonic values suggest that these layers are shale and the relatively low GR suggests that these shales must be relatively rich in non-radioactive clay minerals such as kaolinite or chlorite. In contrast, the Lista Shale sits in medium GR and low neutron areas (marked as area $C$ on Figure 13). As stated, the lowermost part of area $C$ probably represents sandstone layers. The higher values in area $\mathrm{C}$ have high gamma for a given neutron value and represent smectite-rich shales with relatively low concentrations of non-radioactive clay minerals, e.g., kaolinite or chlorite.

The overall similarity of both the density log data (RHOB) and sonic (DTCO) log data, apparent in Figure 13, is proven in Figure 14A, which directly compares Lista and Rodby Shale DTCO to RHOB with symbol size representing the NPHI value. Figure 14A has been annotated to indicate patterns of increasing shale content and increasing porosity (in reservoir sections). Clearly, the intervals selected are not reservoir except that some Lista samples (bottom part of the figure) probably represent thin sand-rich layers.

Differences between the Lista and the Rodby Shales are more apparent in the comparison of Vshale (Equation (3)) and Nshale (Equations (4) and (5)) in Figure 14B. An increasing quantity of 
clay is demonstrated by data moving the origin (lower left) to the upper right. However, the Nshale and Vshale values reveal different attributes of the two rock units. The Rodby data tend to sit in the upper part of the diagram, whereas some of the Lista data tend to plot to the right, towards the area representing smectite- and illite-rich clay minerals. On this basis, we can conclude that the Lista Shale contains less chlorite and kaolinite than the Rodby Shale (and vice versa). This difference was hinted at in the logs from each well (Figures 3-5 and 7) where the separation between the Nshale and Vshale was greater for the Rodby Shale (Figures 3-5) than the Lista Shale (Figure 7). This subtle difference in mineralogy may be important as kaolinite and chlorite are non-expanding clay minerals; the two shale lithologies may have slightly different responses to drying, e.g., when in contact with anhydrous super-critical $\mathrm{CO}_{2}$. Conversely, chlorite is likely to be more geochemically reactive to $\mathrm{CO}_{2}$ than other clay minerals [33] as chlorite is rich in divalent metals such as $\mathrm{Mg}$ and Fe.

\subsection{Comparison of Core Analysis (MICP) Characteristics of the Rodby and Lista Shales}

\subsubsection{Porosity}

The porosity of the Rodby and Lista Shales is relatively high at between 13 and $17 \%$, as demonstrated by both MICP and density log-derived porosity data (Figures 3-8 and Table 2). This is approximately in alignment with published compaction curves for shales that show that porosity can be up to $20 \%$ for rocks at approximately $7000 \mathrm{ft}$ [34]. Such high porosities are typical of shales that have undergone only mechanical compaction with little chemical compaction [35]. Note that chemical compaction tends to occur in rocks hotter than approximately $80^{\circ} \mathrm{C}$, so the relatively high porosity in the Lista and the Rodby Shales confirms that these rocks have not been buried deeper and not been hotter than they are at the present day.

We have compared mercury intrusion-derived porosity (Table 2) and mean pore throat radius (Figure 8) to assess the possible relationship between porosity and indicators of flow properties (Figure 15). These data have been plotted as a function of Vshale to assess whether the proportion of clay minerals (Vshale) influences porosity or pore throat radius (Figure 15A). It is apparent that there is no simple relationship between these porosity or pore throat radius; there is also no relationship between porosity and derived permeability (Table 2).
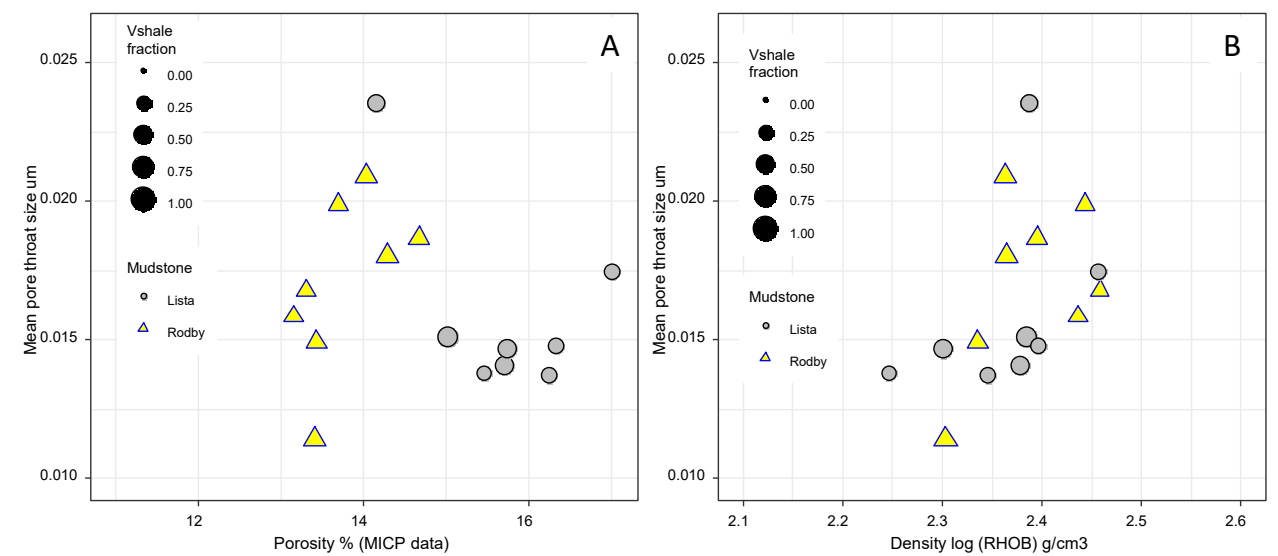

Figure 15. Mercury intrusion porosimetry (MICP) data linked to wireline log data. Diagrams prepared using R-studio-ggplot2 software [15]. (A) Comparison of porosity and mean pore throat size, from MICP analyses, subdivided by Vshale for the Rodby and Lista Shales, represented by the sizes of the symbols. The Lista Shales tend to have a slightly higher porosity than the Rodby Shale, but they tend to have broadly similar mean pore throat diameters. Lower Vshale seems to equate to slightly higher porosity but has no relationship to mean pore throat size. (B) Comparison of density log porosity (RHOB) and mean pore throat size, from MICP analyses, subdivided by Vshale for the Rodby and Lista Shales, represented by the sizes of the symbols. There seems to be positive relationship between bulk density and pore throat size with no simple differences between the Rodby and Lista Shales. 
We have also compared the bulk density of the MICP samples to mean pore throat radius (Figure 15B). There seems to be a weak positive relationship between bulk density (RHOB) and mean pore throat radius. Bulk density reflects both porosity and average matrix density [16]. The Rodby Shales contain more of the relatively high-density mineral calcite than the Lista (Figures 10 and 11), so the relationship maybe coincidental instead of being of great significance.

\subsubsection{Permeability}

Permeability values for the Lista and Rodby Shales, derived from the MICP data and the approach used by Swanson [30], are listed in Table 2. The mean permeability for the Lista Shale is $0.26 \pm 0.16 \mu \mathrm{D}$. The mean permeability for the Rodby Shale is $0.23 \pm 0.07 \mu \mathrm{D}$. The mean permeability values of the Lista and Rodby Shales are therefore broadly similar.

Permeability has been plotted as a function of porosity for the Lista and Rodby Shales (Figure 16). This figure illustrates the similar permeabilities but the slightly higher porosity values of the Lista compared to the Rodby Shales. For comparison, we have also added equivalent data for the top-seal to the Krechba CCS site in Algeria [36] and the top-seal (Mercia Mudstone) to possible Lower Triassic sandstone CCS sites in the UK [37]. Porosity-permeability trend lines have also been added for different types (lithofacies) of fine-grained rocks based on data published by Neufelder, et al. [38]. These trend lines reveal how a given shale, or silty mudstone, should evolve with progressive compactional or cementational porosity loss. The Lista and Rodby Shales sit between the trend lines for true shale and silty mudstone. Given the mineralogy and variably silty but clay mineral-rich textures shown in Figures 10 and 11, this seems to be correct. The Lista samples can be interpreted to be slightly less silty than the Rodby samples, as they have a slightly higher porosity but similar permeability (Figure 16).

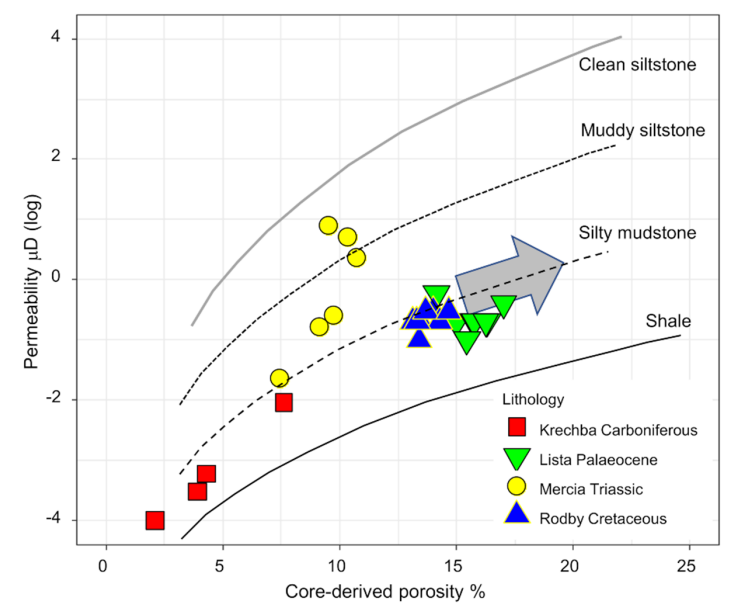

Figure 16. Permeability, in microDarcies, and percentage porosity derived from the mercury intrusion data from the Lista and Rodby Shales compared to equivalent data from the Carboniferous top-seals at the Krechba InSalah CCS site in Algeria [36] and from Upper Triassic Mercia Mudstone top-seals to potential Sherwood Sandstone CCS reservoirs, UKCS [37]. These four shales have been compared to published porosity and permeability trends for different fine-grained clastic lithologies [38], modelled as shale, silty mudstone, muddy siltstone and clean siltstone. The Palaeocene Lista Shale has a slightly higher porosity than the Cretaceous Rodby Shale, probably as it is younger and has not had sufficient time to compact. Although the Lista and Rodby Shales have relatively high porosity, they lie on a rationale porosity-permeability trajectory largely between silty mudstone and shale. The Lista and Rodby Shales have a higher porosity and permeability than the Carboniferous top-seal at the Krechba site because they are younger and have not been as hot resulting in less compaction and mineral diagenesis. Some of the Mercia Mudstone samples are silt rich with the consequent poor sorting leading to higher permeability but lower porosity than the Lista and Rodby mudstones. This diagram can be used to help predict the consequence of porosity-enhancement, due to $\mathrm{CO}_{2}$-induced mineral dissolution, on permeability (see grey arrow). 
Given the position of the data compared to the compaction-cementation-porosity-loss trends on Figure 16, the Lista and Rodby Shales seem to belong to roughly the same lithofacies as the Krechba Carboniferous (Tournasian, $350 \mathrm{Ma}$ ) top-seal (true shale to silty mudstone). The Krechba samples have much lower porosity and permeability than the Lista and Rodby Shales, the difference probably resulting from: (1) the greater time for compactional and cementational porosity loss to have occurred and (2) the Krechba samples have been buried significantly deeper (>3200 $\mathrm{m}$ ) and reached temperatures higher temperatures (well in excess of $100^{\circ} \mathrm{C}$ ) than the Lista and Rodby Shales (Figure 2), thus further enabling more cementational porosity loss.

The Lista and Rodby Shales have a higher porosity than the Upper Triassic Mercia Mudstone samples (Figure 16). This may be a result of the greater time (100 to $140 \mathrm{Myr}$ ) for compactional and cementational porosity loss to have occurred in the Upper Triassic mudstones compared to the Lower Cretaceous and Palaeocene shales. However, the Mercia Mudstone samples have relatively high permeability compared to the Lista and Rodby Shales; this is probably the consequence of the Mercia having a significantly higher silt content [37,39].

\subsection{Comparison of the Mineralogy of the Rodby and Lista Shales and Relationships to Wireline Log Characteristics}

Comparison of SEM-EDS-derived mineralogy data for the Rodby and Lista Shales reveals significant differences. The radioactive/non-radioactive clay mineral index, smectite/(smectite + kaolinite), has been compared to the mica index, muscovite/(muscovite + biotite), with data differentiated by the quantity of rutile and split between the Lower Cretaceous Rodby Shale, calcite-rich Rodby Shale, and intra-Captain Sola Shale and the Palaeocene Lista Shale (Figure 17A). The Lista Shale samples have low rutile concentrations, suggesting different sediment provenance than the Lower Cretaceous Shales. This is not surprising given the 50-60 Myr time gap between deposition of these shales. Less rutile tends to reflect a less mafic source sediment [40]. The Lista Shales tend to have relatively high smectite/(smectite + kaolinite) values; this accords with the wireline log patterns in Figures 13 and 14B. The Lower Cretaceous Sola Shale and Rodby Shales have the lowest smectite/(smectite + kaolinite) ratios, explaining the low Vshale and high Nshale responses of these shales (and see comparison of log data in Figure 14B). Biotite dominates muscovite in all shales. The overall inverse correlations suggest that the sediment with a higher muscovite concentration produces shale with a higher kaolinite content; this suggests that there may be a genetic link between the two minerals, i.e., kaolinite is derived from muscovite somewhere in the hinterlands.

We have compared a feldspar index (plagioclase/(plagioclase + K-feldspar)) to an index of smectite/(smectite + muscovite), with data differentiated by absolute quartz quantities and split between various the Lower Cretaceous Rodby Shale, calcite-rich Rodby Shale, and intra-Captain Sola Shale and the Palaeocene Lista Shale (Figure 17B). The Lista Shales tend to have high plagioclase/(plagioclase + K-feldspar) values compared to the Rodby Shale. Plagioclase can contain calcium, which is reactive to the acidic fluids that result from $\mathrm{CO}_{2}$ injection, so the Lista Shales may be reactive, over a long timescale, to $\mathrm{CO}_{2}$ [41-43]. The Lista Shales tend to have higher quartz concentrations than most of the Lower Cretaceous shales, as illustrated in Figures 10 and 11. Some of the calcite-rich Rodby samples have negligible clay apart from smectite and have relatively high plagioclase/(plagioclase + K-feldspar) ratios; the calcite-rich layers in the Rodby Shale may have undergone a different diagenetic history than the calcite-poor rocks [44]. 

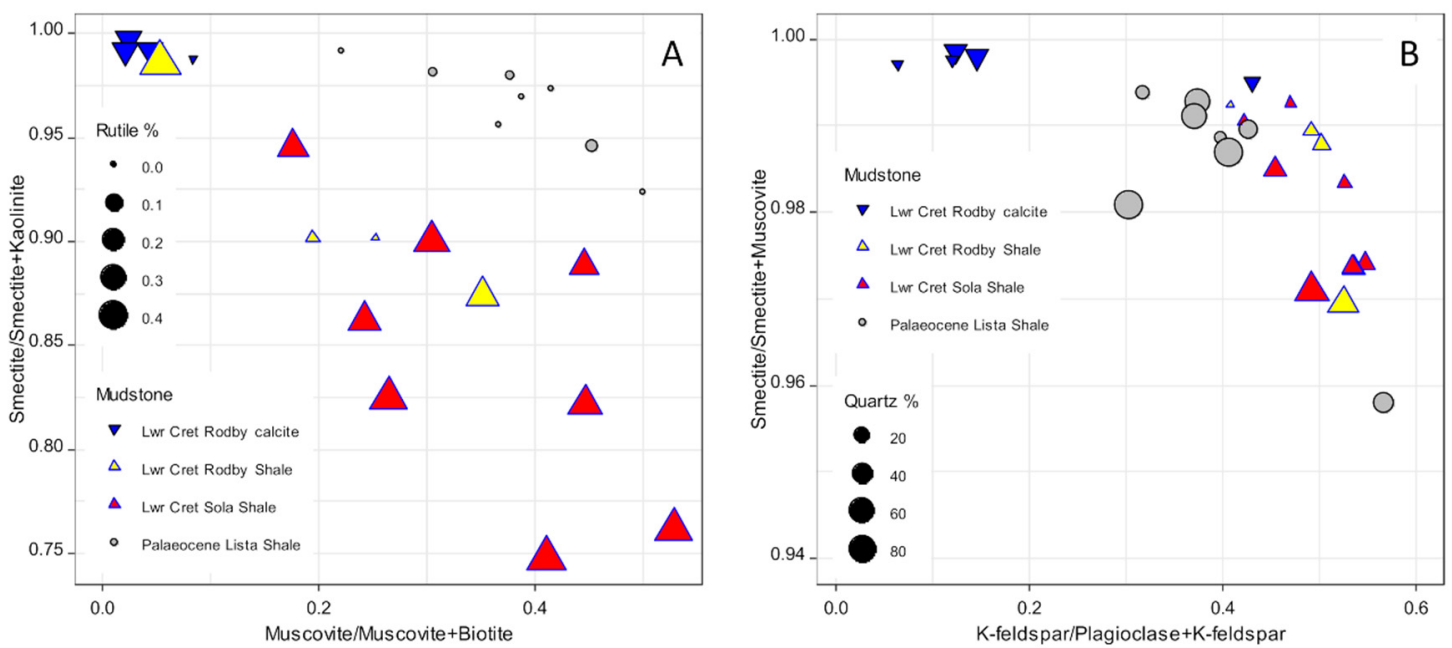

Figure 17. Comparison of SEM-EDS-derived mineralogy data for the Rodby and Lista Shales. Diagrams prepared using R-studio-ggplot2 software [15]. (A) muscovite/(muscovite + biotite) versus smectite/(smectite + kaolinite), with data differentiated by absolute rutile quantities, represented by the sizes of the symbols, and split between various the Lower Cretaceous Rodby Shale, calcite-rich Rodby Shale, and intra-Captain Sola Shale and the Palaeocene Lista Shale. The Lista Shales have universally low rutile concentrations, suggesting different sediment provenance than the Lower Cretaceous Shales. The Lista Shales tend to have universally low smectite/(smectite + kaolinite) values explaining the wireline log patterns in Figures 13 and 14B. The Lower Cretaceous Sola Shale and Rodby Shales have the lowest smectite/(smectite + kaolinite) ratios explaining the low gamma (and Vshale) responses of these shales. Biotite dominates muscovite in all shales with the highest relative biotite concentrations in the calcite-rich Rodby. The overall inverse correlations suggest that the sediment with a higher muscovite concentration produces shale with a higher kaolinite content implying a genetic link between the two minerals. (B) plagioclase/(plagioclase $+\mathrm{K}$-feldspar) versus smectite/(smectite + muscovite), with data differentiated by absolute quartz quantities, represented by the sizes of the symbols, and split between various the Lower Cretaceous Rodby Shale, calcite-rich Rodby Shale, and intra-Captain Sola Shale and the Palaeocene Lista Shale. The Lista Shales tend to have relatively high plagioclase/(plagioclase + K-feldspar) values compared to the Rodby Shale, possibly rendering them more reactive to acidic fluids as might result from $\mathrm{CO}_{2}$ injection. The Lista Shales tend to have higher quartz concentrations than most of the Lower Cretaceous shales. Most of the Rodby calcite-rich samples have negligible clay apart from smectite and have relatively high plagioclase/(plagioclase + K-feldspar) ratios; the calcite-rich layers have probably undergone a different diagenetic history than the calcite-poor rocks. Increasing muscovite tends to equate to increasing K-feldspar, suggesting that these K-rich minerals derive from similar sources.

A comparison of the index smectite/(quartz + smectite) to plagioclase/(plagioclase + K-feldspar), with data differentiated by absolute kaolinite quantities and split between various the Lower Cretaceous Rodby Shale, calcite-rich Rodby Shale, and intra-Captain Sola Shale and the Palaeocene Lista Shale further reveals differences between the Rodby and Lista Shales (Figure 18A). The highest kaolinite concentrations have relatively low plagioclase/(plagioclase + K-feldspar) values and high smectite/(quartz + smectite) values; thus, increasing kaolinite equates to more smectite and relatively low plagioclase concentrations. The Lista Shales tend to have a relatively high $\mathrm{CO}_{2}$-reactive plagioclase concentration compared to the Rodby Shale. To reinforce the calcite enrichment of the Rodby Shale, calcite has also been compared to smectite/(quartz + smectite) (Figure 18B). Calcite may initially be dissolved in association with water and elevated $\mathrm{CO}_{2}$ concentrations, as shown by CO2-EOR (enhanced oil recovery) projects [43], so accessible parts of the Rodby Shale maybe somewhat susceptible to increasing porosity and permeability and decreasing stiffness (see later section on rock strength) if $\mathrm{CO}_{2}$ is injected. 

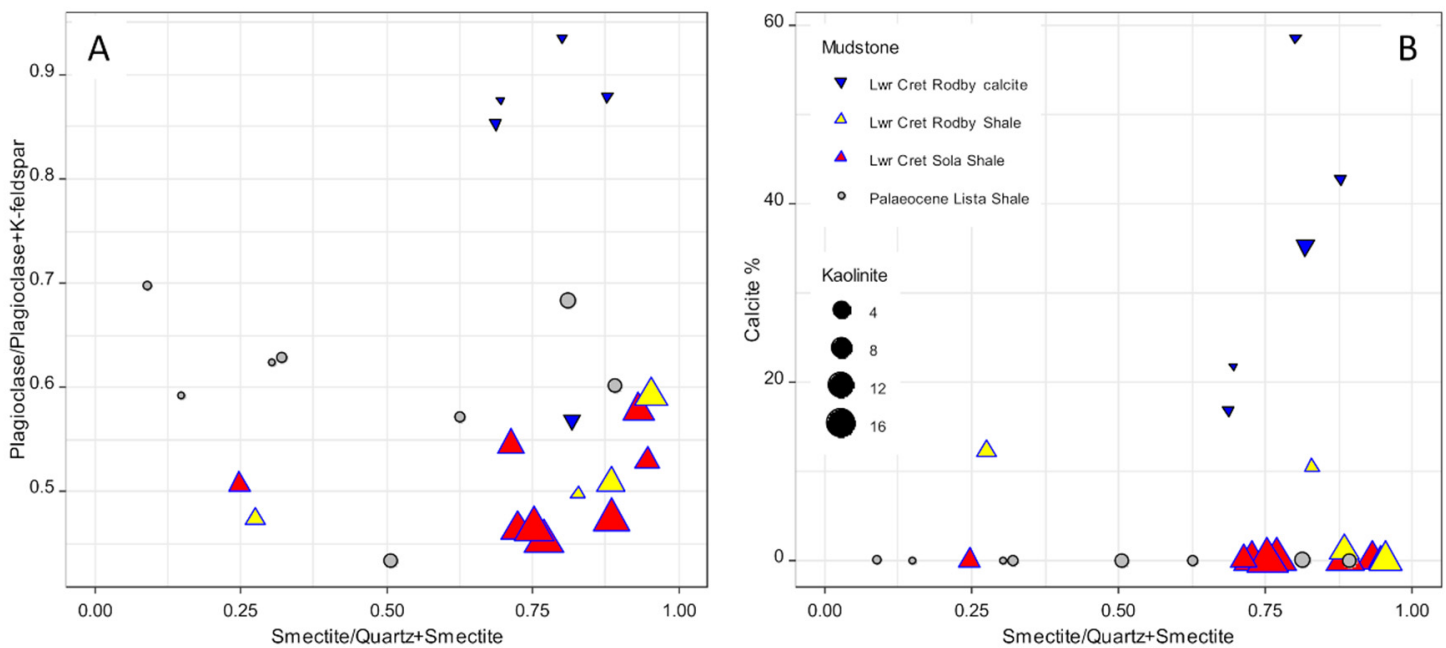

Figure 18. Comparison of SEM-EDS-derived mineralogy data for the Rodby and Lista Shales. Diagrams prepared using R-studio-ggplot2 software [15]. (A) smectite/(quartz + smectite) versus high plagioclase/(plagioclase + K-feldspar) ratios with data differentiated by absolute kaolinite quantities, represented by the sizes of the symbols, and split between various the Lower Cretaceous Rodby Shale, calcite-rich Rodby Shale, and intra-Captain Sola Shale and the Palaeocene Lista Shale. The highest kaolinite concentrations are associated with relatively low plagioclase/(plagioclase $+\mathrm{K}$-feldspar) values and high smectite/(quartz + smectite) values. The Lista Shales tend to have relatively high plagioclase/(plagioclase + K-feldspar) values compared to the Rodby Shale, possibly rendering them more reactive to acidic fluids as might result from $\mathrm{CO}_{2}$ injection. (B) smectite/(quartz + smectite) versus total calcite with data differentiated by absolute kaolinite quantities, represented by the sizes of the symbols, and split between various the Lower Cretaceous Rodby Shale, calcite-rich Rodby Shale, and intra-Captain Sola Shale and the Palaeocene Lista Shale. These shales can have a wide variety of smectite/(smectite + quartz) values. As expected, the Rodby calcite-cemented samples are easily discerned from this plot but almost all Rodby samples contain calcite.

\subsection{Maximum $\mathrm{CO}_{2}$ Column Heights Possible under the Rodby and Lista Shale Top-Seals}

The mercury intrusion data, listed in Table 2, have been used to derive maximum $\mathrm{CO}_{2}$ column heights in a similar way that they are used to determine oil and gas column heights [24].

It is first necessary to convert the air-mercury threshold pressure values $\left(\mathrm{P}_{\mathrm{a}-\mathrm{m}}\right)$ into equivalent brine- $\mathrm{CO}_{2}$ threshold pressure values $\left(\mathrm{P}_{\mathrm{b}-\mathrm{c}}\right)$ using the formula [26,45]:

$$
\mathrm{P}_{\mathrm{b}-\mathrm{c}}=\mathrm{P}_{\mathrm{a}-\mathrm{m}} \cdot \frac{\sigma_{\mathrm{b}-\mathrm{c}} \cdot \cos \theta_{\mathrm{b}-\mathrm{c}}}{\sigma_{\mathrm{a}-\mathrm{m}} \cdot \cos \theta_{\mathrm{a}-\mathrm{m}}}
$$

where $\sigma_{\mathrm{b}-\mathrm{c}}$ is the interfacial tension between brine and $\mathrm{CO}_{2} ; \sigma_{\mathrm{a}-\mathrm{m}}$ is the interfacial tension between air and mercury, as used in the test rig; $\cos \theta_{\mathrm{b}-\mathrm{c}}$ is the cosine of the contact angle (in radians) between brine and $\mathrm{CO}_{2}$; and $\cos \theta_{\mathrm{a}-\mathrm{m}}$ is the cosine of the contact angle (in radians) between air and mercury. The interfacial tension between brine and $\mathrm{CO}_{2}$ varies between 0.021 and $0.027 \mathrm{~N} / \mathrm{m}$ and interfacial tension between air and mercury is $0.481 \mathrm{~N} / \mathrm{m}[26,45,46]$. The contact angle between brine and $\mathrm{CO}_{2}$ was assumed to be $115^{\circ}$ [26] and the contact angle between air and mercury is $140^{\circ}$ for smectite-rich mudstones [47].

After this conversion, the capillary pressure data for the brine- $\mathrm{CO}_{2}$ system can be used to determine the $\mathrm{CO}_{2}$ column height $\left(\mathrm{T}_{\mathrm{h}}\right)$ that corresponds to a specific capillary pressure which an underlying reservoir can retain before the seal begins to leak, using the equation [26]:

$$
\mathrm{T}_{\mathrm{h}}=\frac{\mathrm{P}_{\mathrm{b}-\mathrm{c}}}{\left(\rho_{\mathrm{b}}-\rho_{\mathrm{c}}\right) \cdot \mathrm{g}}
$$


where $\rho_{\mathrm{b}}$ is the density of the brine, $\rho_{\mathrm{c}}$ is the density of $\mathrm{CO}_{2}$ and $\mathrm{g}$ is acceleration due to gravity. Based on formation water compositions for those parts of the North Sea [17], brine density was assumed to be $1.05 \mathrm{~g} / \mathrm{cm}^{3}$ for both Acorn and East Mey sites. The density of $\mathrm{CO}_{2}$ was assumed to be $0.65 \mathrm{~g} / \mathrm{cm}^{3}$ [31].

Calculated maximum column heights for the eight Lista Shale top-seal samples range from 166 to $471 \mathrm{~m}$, with a mean of $385 \mathrm{~m}$ (Table 2). Calculated maximum column heights for the eight Rodby Shale top-seal samples range from 315 to $583 \mathrm{~m}$, with a mean of $396 \mathrm{~m}$ (Table 2). These mean values are broadly comparable; the similarity is expected given the resemblance of the pore size distribution curves for the two shales (Figure 8). These maximum column heights exceed closure of the petroleum trapping structures, suggesting that escape of the injected $\mathrm{CO}_{2}$ via the top-seals at both sites is highly unlikely. Note that accumulations of continuously connected $\mathrm{CO}_{2}, 100$ s of metres thick beneath top-seals, might not be the norm given that intraformational capillary trapping of isolated ganglia of $\mathrm{CO}_{2}$ seems to be common [4], thus making leakage of $\mathrm{CO}_{2}$ via top-seals even more unlikely.

\subsection{Mineralogical Rock Strength Indicators for the Rodby and Lista Shales}

It is important to understand the mechanical properties of storage sites to be used for Carbon Capture and Storage. Perhaps surprisingly, there are no simple relationships between the splitting tensile strength (STS) data displayed in Figure 12 and mineralogy (SEM-EDS or XRD; Figures 9-11, 16 and 17), log-derived properties (Figures 3-7, 13 and 14) or the results of mercury intrusion porosimetry (Figures 8 and 15, Table 2). This may result from the lack of significant range of STS values. It is noteworthy that the measured STS values are low compared to previously published values; for example, DeReuil, Birgenheier and McLennan [32] reported values from 6 to $18 \mathrm{MPa}$ (mean approximately $13 \mathrm{MPa}$ ) compared to the mean value of approximately $2.5 \mathrm{MPa}$ for both the Lista and Rodby Shales (Figure 12). The samples measured by DeReuil, Birgenheier and McLennan [32] show porosity values of below detection to approximately $3 \%$, suggesting that the uniformly high porosity of the Lista and Rodby Shales is the primary control on splitting tensile strength.

There has been much interest in the relationship between mineralogy and geomechanical properties, as mineralogy can be assessed from cuttings in real time during drilling. We have calculated two pseudo-functions from SEM-EDS mineralogy data that relate to various geomechanical parameters. The sum of quartz, feldspars and pyrite, from XRD or SEM-EDS data, has been shown to be proportional to Young's modulus for mudstones [48]. Brittle minerals include quartz, feldspars, calcite and mica; ductile minerals include all clay minerals. Rybacki, et al. [49], based on Jin, et al. [50], reported that the relative brittleness of a formation can be assessed by comparing the sum of brittle minerals to the sum of brittle and ductile minerals. Figure 19 compares the Lista and Rodby Shale samples (and Sola Shales) and shows that the mineralogically based Brittleness Index tends to increase with Young's Modulus strength except for calcite rich samples in the Rodby Shale. The Lista Shale appears to have a higher Young's modulus than most of the Rodby and Sola Shale samples. The difference in the geomechanical attributes of the Lista and Rodby Shales should be accounted for in comparative forward models of $\mathrm{CO}_{2}$ injection into the Acorn and East Mey CCS sites.

\subsection{Log-Derived Rock Strength Indicators for the Rodby Shale}

Unfortunately, no sonic shear logs were collected during the drilling of the two East Mey wells used in this study. However, two wells from the Acorn CCS site have a full suite of logs that lend themselves to the assessment of geomechanical rock properties. 


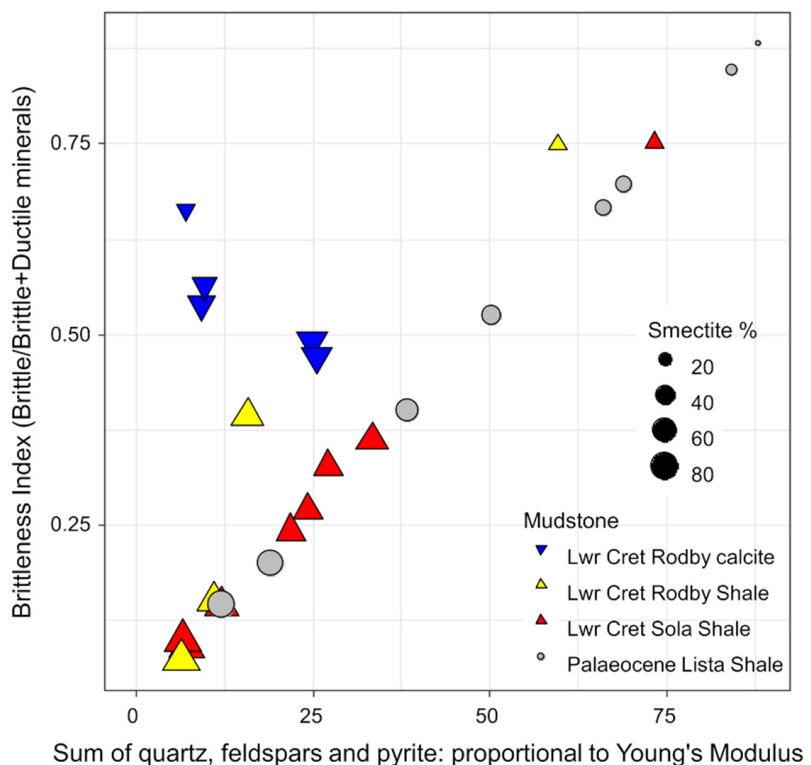

Figure 19. Comparison of SEM-EDS data in terms of pseudo-functions that relate to various geomechanical parameters. The sizes of all symbols represents the quantity of smectite. Diagram prepared using R-studio-ggplot2 software [15]. The sum total of quartz, feldspars and pyrite has been shown to be proportional to Young's modulus for mudstones [48]. The brittleness calculation is based on [49] and [50]. Brittle minerals include quartz, feldspars, calcite and mica; ductile minerals include all clay minerals. The brittleness tends to increase with Young's modulus strength except for calcite rich samples in the Rodby Shale. The Rodby Shale appears to be more brittle than the Lista Shale due to the relatively high concentration of calcite in the former.

The geomechanical variable, Poisson's ratio (V, lateral strain divided by longitudinal strain), was determined, following Rider and Kennedy [16], using:

$$
\text { Poisson's ratio }(\mathrm{V})=\frac{0.5 \times\left[\frac{\mathrm{DTS}}{\mathrm{DTCO}}\right]^{2}-1}{\left[\frac{\mathrm{DTS}}{\mathrm{DTCO}}\right]^{2}-1}
$$

where DTS and DTCO are the shear and compressional sonic velocity measurements reported from downhole logs (Table 1; Figures 3 and 4). The geomechanical variable, shear modulus (G, applied stress divided by applied strain), was determined following Rider and Kennedy [16], using:

$$
\text { Shear modulus }(\mathrm{G})=1.34 \times 10^{10} \times \frac{\rho_{\mathrm{b}}}{\mathrm{DTS}^{2}}
$$

where $\rho_{\mathrm{b}}$ is the log-derived bulk density (Figures 3 and 4). Finally, the geomechanical variable, Young's modulus (E, applied uniaxial stress divided by normal strain), was determined again using Rider and Kennedy [16]:

$$
\text { Young's modulus }(\mathrm{E})=2 \mathrm{G}(1+\mathrm{V})
$$

where $\mathrm{G}$ is the shear modulus derived from Equation (10) and V is the Poisson's ratio derived from Equation (9).

With this approach, it is possible to derive fundamental geomechanical elastic properties, relating stress to strain, and compare these to other rock properties derived using wireline logs, as long as elastic isotropy is assumed. Note that the tensile splitting strength values display anisotropy (Figure 12), so the assumption of elastic isotropy is unlikely to be correct. However, the log data derive from subvertical wells and most bedding is subhorizontal, so the comparison remains valid. Here we have derived Young's modulus for the Rodby Shale and compared it to the gamma signal, with data subdivided by 
the neutron value and by density log-derived porosity (Figure 20A). As gamma and neutron increase, the Young's modulus decreases to very low values that are an order of magnitude lower than the shales reported by DeReuil, Birgenheier and McLennan [32]. Increasing clay content, as reflected by both gamma and neutron results in Young's modulus values as low as $5 \mathrm{GPa}$. There are a few data points on Figure 20A that have low gamma, low neutron and very low density log-derived porosity that have some high Young's modulus values (approaching $50 \mathrm{GPa}$ ). These are calcite-cemented horizons visible in the interpreted logs in Figures 3-7.
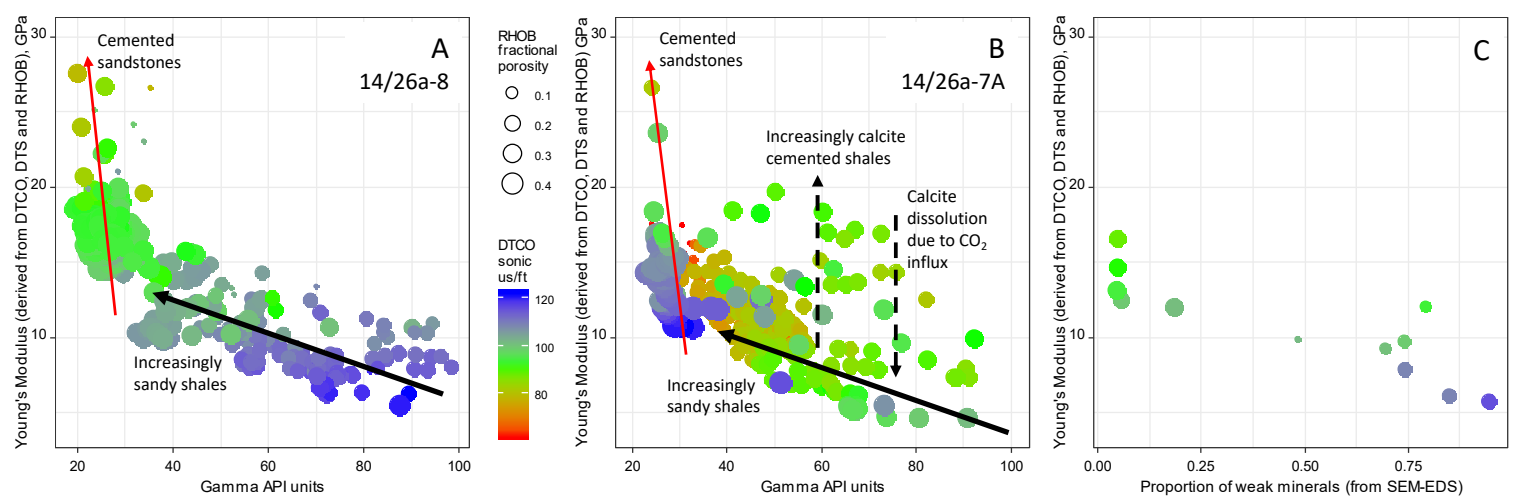

Figure 20. Comparison of clay mineral indicators to Young's modulus indicator for the Rodby Formation. Diagram prepared using R-studio-ggplot2 software [15]. (A) Wireline log-derived Young's modulus, derived for Rodby Shale data from 14/26a-8 via compressional and shear sonic log data and density log data, using Equations (9)-(11), defined in Rider and Kennedy [16], plotted versus gamma ray $\log$ data with the data differentiated by density log-derived porosity and compressional sonic log data. The solid black arrow shows that decreasing shale gamma corresponds to higher Young's modulus values; decreasing compressional sonic (DTCO) and porosity also lead to higher Young's modulus. For reference, the red arrow corresponds to increasingly cemented sandstones that achieve ever higher Young's modulus values. For a given shale gamma ray value (i.e., for a fixed clay mineral content), Young's modulus increases as sonic and porosity values decrease as these represent more compact rock that may have a greater quantity of calcite (and see Figure 10). (B) Wireline log-derived Young's modulus, derived for Rodby Shale data from 14/26a-7A, equivalent to the data in Figure 20A. The solid black and red arrows reveal the same patterns as in 14/26a-8; the dashed black arrows show that some part of the Rodby in this well (lithology proven by high gamma) have relatively high Young's modulus, but these intervals have a slightly lower porosity and have lower sonic values, demonstrating that these shales have undergone localised cementation (probably by calcite). There are no equivalent data for the two Lista wells, since shear sonic (DTS) logs were not taken. (C) Wireline log-derived Young's modulus, derived for Rodby Shale data from 14/26a-8, using the same method as part A [16], compared to the SEM-EDS-derived proportion of weak minerals (sum of all clay minerals). Although there are clearly fewer data in part $C$, it displays the same overall pattern as parts A and B. This figure suggests that it may be possible to predict Young's modulus (rock strength) for shale, based on gamma, density, and compressional sonic logs, even when shear sonic log data are not available.

To prove the link between clay content and Young's modulus, we have taken the subset of samples with SEM-EDS data and summed the clay (ductile) minerals and then compared this to the log-derived Young's modulus (Figure 20C). Although there are far fewer data points, the relationship is the same as in Figure 20A. This similarity supports the use of wireline log data to derive the fundamental geomechanical rock properties of top-seal lithologies to CCS sites.

\section{Synthesis}

From the observations made here and in other studies [33], two factors appear to be potentially important for the viability of the shale top-seals at the Acorn and East Mey CCS sites. The first factor is the quantity of carbonate, which in this case means the quantity of calcite but could also include 
siderite, since carbonate minerals can dissolve in $\mathrm{CO}_{2}$-enriched pore waters $[33,41,43,51]$. The second factor is the quantity of chlorite in the shales, since chlorite, an Fe-Mg-rich clay mineral, well known to be soluble in weak acids $[52,53]$, has been shown to dissolve in low-permeability cores flooded with $\mathrm{CO}_{2}$-saturated water [33].

In shales such as the Rodby Shale at the Acorn site, dissolution of calcite or siderite during an influx of $\mathrm{CO}_{2}$ will increase permeability (as a result of the inevitable increase in porosity due to calcite dissolution) and decrease the rock strength, in terms of Young's Modulus, as a result of the weakening effect demonstrated in this study by reference to Figure 20A,B. Similarly, shales rich in chlorite will undergo reactions with $\mathrm{CO}_{2}$, increasing porosity and permeability (Armitage et al. 2013).

We can therefore consider these factors as having a dynamic relationship with two competing types of permeability - the potential for fracture enhanced permeability and pore network permeability. We have here schematically illustrated this conceptual model by considering four theoretical end-member shale top-seal types (Figure 21): (1) silty shales rich in quartz and feldspar, or highly quartz-cemented shales will have initially low matrix permeability and are unreactive with $\mathrm{CO}_{2}$, so the Young's modulus and the potential for fracture-enhanced permeability remain high. (2) Calcite-rich shales will also have low initial matrix permeability and are relatively brittle; an influx of $\mathrm{CO}_{2}$ will result in removal of calcite through dissolution thus enhancing matrix permeability, decreasing Young's modulus, and so decreasing the potential for fracture permeability. (3) Chlorite-rich shales will be initially ductile and not prone to fracturing, but they will undergo reactions with $\mathrm{CO}_{2}$ and so increase matrix permeability. There is likely to be a relatively muted effect of Young's modulus and potential for fracture permeability in chlorite-rich shales. (4) A fourth shale type is rich in non-chlorite clay, which has a low Young's modulus (limited fracture potential) and is unreactive, and so does not alter matrix or risk of fracture permeability despite $\mathrm{CO}_{2}$ influx.

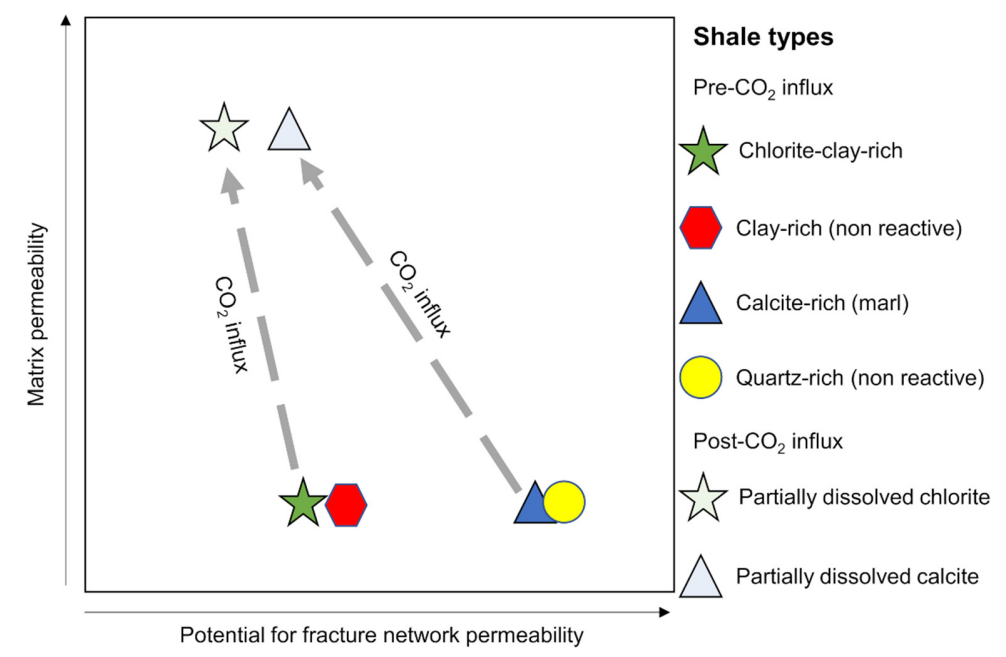

Figure 21. Conceptual model for the potential dynamic permeability changes resulting from $\mathrm{CO}_{2}$ influx for four theoretical shale types: (1) chlorite-rich shale, (2) smectite-illite-kaolinite (clay)-rich shale (i.e., non-reactive-clay minerals), (3) calcite-rich shale, (4) quartz-K-feldspar-silt-rich shale (non-reactive). The more ductile chlorite-rich and non-reactive clay-rich shales will be less likely to be brittle and undergo fracture-enhanced permeability than calcite- and quartz-bearing shales due to $\mathrm{CO}_{2}$ injection-enhanced pore fluid pressure increase. $\mathrm{CO}_{2}$ influx is likely to enhance porosity and thus permeability and decrease the likelihood of fracture permeability due to increased fluid pressure in the calcite- and chlorite-rich shales as they react with $\mathrm{CO}_{2}$.

The conceptual model in Figure 21 is simplified and the real system is dynamic and complex. For example, as fluids enter pore space, local stresses may result in fracture even in a rock with a lower overall Young's modulus. Similarly, the samples presented here, from the Rodby and Lista Shales, show significant mineralogical heterogeneity; understanding how the system acts as whole 
will be fundamental to the effective appraisal of shale cap rocks for $\mathrm{CO}_{2}$ storage. The conceptual model presented in Figure 21 does, however, highlight areas for further study as hydrocarbon cap rock concepts are further applied to $\mathrm{CO}_{2}$ storage sites.

\section{Conclusions}

1. The Lower Cretaceous Rodby Shale and Palaeocene Lista Shale are top-seals to planned Carbon Capture and Storage (CCS) sites, offshore NE Scotland, UK. Both have acted as effective top-seals to petroleum accumulations, offshore Scotland. The use of pore size distribution data resulting from mercury intrusion porosimetry suggests that both top-seals can successfully contain $\mathrm{CO}_{2}$ column heights of approximately $390 \mathrm{~m}$.

2. The Lower Cretaceous Rodby Shale at the Acorn CCS site has an overall porosity of approximately $14 \%$ and a suite of clay minerals dominated by smectite but also including non-radioactive clay minerals such as kaolinite. The Palaeocene Lista Shale at the East Mey CCS site has a higher overall porosity of approximately $16 \%$ and a suite of clay minerals dominated by smectite with only minor quantities of non-radioactive clay minerals such as kaolinite. Despite the difference in porosities, the Lista and Rodby Shales have similar permeabilities. Porosity-permeability values for both the Lista and Rodby Shales are typical of silty mudstone to shale lithologies.

3. The dominant non-clay mineral in the Rodby Shale is calcite, with more than $50 \%$ calcite found in some samples. The calcite is composed of both intact microfossil tests and disseminated calcite patches, typically smaller than approximately $100 \mu \mathrm{m}$. In contrast, the dominant non-clay mineral in the Lista Shale is quartz; the Lista contains no calcite. The quartz is present as clay and silt-grade grains, typically smaller than approximately $10 \mu \mathrm{m}$ but locally present up to 60 to $80 \mu \mathrm{m}$.

4. Despite the difference in ages and mineralogy, the Rodby and Lista Shale seem to have similar mean pore throat radius values (approximately $18 \mathrm{~nm}$ ) and have similar splitting tensile strength (approximately $2.5 \mathrm{MPa}$ ) and exhibit similar anisotropic values of splitting tensile strength. Conversion of mineral quantities into geomechanical attributes suggests that the Lower Cretaceous Rodby Shales may be less brittle and have a lower Young's modulus than the Cenozoic Lista Shales.

5. Elastic property analysis from wireline log data, here derived only for the Lower Cretaceous shales (as no shear sonic logs were available for the examined Cenozoic wells), reveals that Young's modulus (rock stiffness) increases with decreasing gamma (lower smectite content) and with decreasing compressional sonic (greater quantity of lower transit time minerals such as calcite). Our work has shown that Young's modulus may be predictable based on gamma, density logs and compressive sonic logs in wells where shear sonic logs were not collected.

6. Four end-member shale types have here been proposed as a function of the reactivity of clay minerals to $\mathrm{CO}_{2}$ (chlorite can potentially dissolve in $\mathrm{CO}_{2}$-rich acidic pore waters) and the reactivity of the non-clay fraction (calcite can also potentially dissolve in $\mathrm{CO}_{2}$-rich acidic waters). The shale types can be classified by their susceptibility to develop fracture permeability, their susceptibility to react with $\mathrm{CO}_{2}$, and their susceptibility to decrease brittleness and increase matrix permeability following reaction with $\mathrm{CO}_{2}$. Based on this novel classification scheme, the Rodby Shale maybe locally reactive to $\mathrm{CO}_{2}$, increasing porosity but decreasing the risk of developing fracture permeability, because the quantity of brittle calcite may be locally reduced. The Lista Shale will be largely inert to $\mathrm{CO}_{2}$ on the basis of its smectite-quartz-dominated mineralogy.

Author Contributions: Conceptualization, R.H.W.; methodology, R.H.W., M.J.A., J.E.P.U. and D.R.F.; validation, R.H.W., M.J.A., J.E.P.U., D.R.F., C.E.B., J.A., N.H., R.S.H., E.M. and S.G.; formal analysis, R.H.W., M.J.A., J.E.P.U. and D.R.F.; investigation, R.H.W., M.J.A., J.E.P.U., D.R.F., C.E.B., J.A., N.H., R.S.H., E.M. and S.G.; data curation, R.H.W. and M.J.A.; writing-original draft preparation, R.H.W.; writing-review and editing, R.H.W., M.J.A., J.E.P.U., D.R.F., C.E.B., J.A., N.H., R.S.H., E.M. and S.G.; supervision, R.H.W., C.E.B., E.M. and R.S.H.; funding acquisition, R.H.W., C.E.B., E.M. and R.S.H. All authors have read and agreed to the published version of the manuscript. 
Funding: The work reported here was part of the Accelerating Carbon Technologies (ACT) Acorn Carbon Capture and Storage (CCS) Project, under the ERA-NET Horizon 2020 programme, project 271500, and was jointly funded by the Department for Business, Energy and Industrial Strategy, United Kingdom; the Research Council of Norway; the Netherlands Enterprise Agency. Juan Alcalde is funded by the Spanish MICINN (Juan de la Cierva fellowship-IJC2018-036074-I). Alan James, CEO of Pale Blue Dot Ltd. (Banchory, UK), is warmly thanked for skilfully leading the Acorn Project and offering advice throughout the project, including during the preparation of this manuscript. We express our warm appreciation to guest editor Jim Buckman (Heriot Watt University, UK) for encouraging us to write and submit this paper. We would like to thank four diligent anonymous reviewers for their thoughtful and constructive comments on the initial version of the manuscript, and academic lead for this thematic issue.

Conflicts of Interest: The authors declare no conflict of interest.

\section{References}

1. Haszeldine, R.S. Carbon Capture and Storage: How Green Can Black Be? Science 2009, 325, 1647-1652. [CrossRef] [PubMed]

2. Alcalde, J.; Flude, S.; Wilkinson, M.; Johnson, G.; Edlmann, K.; Bond, C.E.; Scott, V.; Gilfillan, S.M.V.; Ogaya, X.; Haszeldine, R.S. Estimating geological $\mathrm{CO}_{2}$ storage security to deliver on climate mitigation. Nat. Commun. 2018, 9. [CrossRef] [PubMed]

3. Harding, F.C.; James, A.T.; Robertson, H.E. The engineering challenges of $\mathrm{CO}_{2}$ storage. Proc. Inst. Mech. Eng. Part A J. Power Energy 2018, 232, 17-26. [CrossRef]

4. Krevor, S.; Blunt, M.J.; Benson, S.M.; Pentland, C.H.; Reynolds, C.; Al-Menhali, A.; Niu, B. Capillary trapping for geologic carbon dioxide storage-From pore scale physics to field scale implications. Int. J. Greenh. Gas Control 2015, 40, 221-237. [CrossRef]

5. Full Chain Development Plan and Budget; Pale-Blue-Dot-Energy: Banchory, UK, 2018.

6. Alcalde, J.; Heinemann, N.; Mabon, L.; Worden, R.H.; Maver, M.; Robertson, H.; Ghanbari, S.; Swennenhuis, F.; Mann, I.; Walker, T.; et al. Developing full-chain industrial carbon capture and storage in a resource- and infrastructure-rich hydrocarbon province. J. Clean. Prod. 2019, 233, 963-971. [CrossRef]

7. Williams, J.D.O.; Fellgett, M.W.; Quinn, M.F. Carbon dioxide storage in the Captain Sandstone aquifer: Determination of in situ stresses and fault-stability analysis. Pet. Geosci. 2016, 22, 211-222. [CrossRef]

8. Marshall, J.D.; Tucker, O.D.; Lovelock, C.E. Goldeneye: Modelling a depleted field for carbon capture-How much uncertainty is left? Pet. Geosci. 2016, 22, 37-45. [CrossRef]

9. ACT Acorn D07 Acorn $\mathrm{CO}_{2}$ Storage Site Development Plan; Pale-Blue-Dot-Energy: Banchory, UK, 2018.

10. ACT Acorn D08 East Mey Storage Site Development Plan; Pale-Blue-Dot-Energy: Banchory, UK, 2018.

11. Copestake, P.; Sims, A.P.; Crittenden, S.; Hamar, G.P.; Ineson, J.R.; Rose, P.T.; Tringham, M.E. Lower Cretaceous. In The Millenium Atlas: Petroleum Geology of the Central and Northern North Sea; Evans, D., Graham, C., Armour, A., Bathurst, P., Eds.; Geological Society of London: London, UK, 2003; pp. 1211-1248.

12. Ahmadi, Z.; Sawyers, M.; Kenyon-Roberts, S.; Stanworth, B.; Kugler, K.; Kristensen, J.; Fugelli, E. Paleocene. In The Millenium Atlas: Petroleum Geology of the Central and Northern North Sea; Evans, D., Graham, C., Armour, A., Bathurst, P., Eds.; Geological Society of London: London, UK, 2003; pp. 1411-1449.

13. Jones, E.; Jones, B.; Ebdon, C.; Ewen, D.; Milner, P.; Plunkett, J.; Hudson, G.; Slater, P. Eocene. In The Millenium Atlas: Petroleum Geology of the Central and Northern North Sea; Evans, D., Graham, C., Armour, A., Bathurst, P., Eds.; Geological Society of London: London, UK, 2003; pp. 1511-1531.

14. Fyfe, A.; Gregersen, U.; Jordt, H.; Rundberg, Y.; Eidvin, T.; Evans, D.; Stewart, D.; Hovland, M.; Andresen, P. Oligocene to Holocene; Geological Society of London: London, UK, 2003; pp. 1611-1632.

15. Wickham, H. Ggplot2: Elegant Graphics for Data Analysis; Springer: Cham, Switzerland, 2016; p. 226.

16. Rider, M.; Kennedy, M.J. The Geological Interpretation of Well Logs; Rider-French Consulting: Cambridge, UK, 2011.

17. Warren, E.A.; Smalley, P.C. North Sea Formation Water Atlas; Geological Society: London, UK, 1994; Volume 15, p. 208.

18. Armitage, P.J.; Worden, R.H.; Faulkner, D.R.; Aplin, A.C.; Butcher, A.R.; Iliffe, J. Diagenetic and sedimentary controls on porosity in Lower Carboniferous fine-grained lithologies, Krechba field, Algeria: A petrological study of a caprock to a carbon capture site. Mar. Pet. Geol. 2010, 27, 1395-1410. [CrossRef] 
19. Pirrie, D.; Butcher, A.R.; Power, M.R.; Gottlieb, P.; Miller, G.L. Rapid quantitative mineral and phase analysis using automated scanning electron microscopy (QemSCAN): Potential applications in forensic geoscience. In Forensic Geoscience: Principles, Techniques and Applications; Pye, K., Croft, D.J., Eds.; Geological Society: Bath, UK, 2004; Volume 232, pp. 123-136.

20. Wooldridge, L.J.; Worden, R.H.; Griffiths, J.; Utley, J.E.P. The origin of clay-coated sand grains and sediment heterogeneity in tidal flats. Sediment. Geol. 2018, 373, 191-209. [CrossRef]

21. Moore, D.M.; Reynolds, R.C., Jr. X-Ray Diffraction and the Identification and Analysis of Clay Minerals; Oxford University Press: Oxford, UK, 1997; p. 378.

22. Hillier, S. Accurate quantitative analysis of clay and other minerals in sandstones by XRD: Comparison of a Rietveld and a reference intensity ratio (RIR) method and the importance of sample preparation. Clay Miner. 2000, 35, 291-302. [CrossRef]

23. Zinszner, B.; Pellerin, F.-M. A Geoscientists Guide to Petrophysics; IFP Publications: Paris, Francis, 2007 ; p. 384.

24. Tiab, D.; Donaldson, E.C. Petrophysics, 4th ed.; Elsevier: Amsterdam, The Netherlands, 2015; p. 894.

25. Heling, D. Micro-fabrics of shales and their rearrangement by compaction. Sedimentology 1970, 17, $247-260$. [CrossRef]

26. Lohr, C.D.; Hackley, P.C. Using mercury injection pressure analyses to estimate sealing capacity of the Tuscaloosa marine shale in Mississippi, USA: Implications for carbon dioxide sequestration. Int. J. Greenh. Gas Control 2018, 78, 375-387. [CrossRef]

27. Blackbourn, G.A. Cores and Core Logging for Geoscientists; Whittles Publishing: Dunbeath, UK, 2012.

28. ASTM-D3967-16. Standard Test Method for Splitting Tensile Strength of Intact Rock Core Specimens; STM International: West Conshohocken, PA, USA, 2016.

29. Allen, M.J.; Faulkner, D.R.; Worden, R.H.; Rice-Birchall, E.; Katirtsidis, N.; Utley, J.E.P. Geomechanical and petrographic assessment of a $\mathrm{CO}_{2}$ storage site: Application to the Acorn $\mathrm{CO}_{2}$ Storage Site, offshore United Kingdom. Int. J. Greenh. Gas Control 2020, 94, 102923. [CrossRef]

30. Swanson, B.F. A simple correlation between permeabilities and mercury capillary pressures. J. Pet. Technol. 1981, 33, 2498-2504. [CrossRef]

31. Salem, A.M.; Shedid, S.A. Variation of petrophysical properties due to carbon dioxide $\left(\mathrm{CO}_{2}\right)$ storage in carbonate reservoirs. J. Pet. Gas Eng. 2013, 4, 91-102. [CrossRef]

32. DeReuil, A.A.; Birgenheier, L.P.; McLennan, J. Effects of anisotropy and saturation on geomechanical behavior of mudstone. J. Geophys. Res. Solid Earth 2019, 124, 8101-8126. [CrossRef]

33. Armitage, P.J.; Faulkner, D.R.; Worden, R.H. Caprock corrosion. Nature Geosci. 2013, 6, 79-80. [CrossRef]

34. Allen, P.A.; Allen, J.R.L. Basin Analysis: Principles and Applications; Wiley-Blackwell: Chichester, UK, 2013.

35. Peltonen, C.; Marcussen, O.; Bjørlykke, K.; Jahren, J. Clay mineral diagenesis and quartz cementation in mudstones: The effects of smectite to illite reaction on rock properties. Mar. Pet. Geol. 2009, 26, 887-898. [CrossRef]

36. Armitage, P.J.; Faulkner, D.R.; Worden, R.H.; Aplin, A.C.; Butcher, A.R.; Iliffe, J. Experimental measurement of, and controls on, permeability and permeability anisotropy of caprocks from the $\mathrm{CO}_{2}$ storage project at the Krechba Field, Algeria. J. Geophys. Res. Solid Earth 2011, 116, B12208. [CrossRef]

37. Armitage, P.J.; Worden, R.H.; Faulkner, D.R.; Butcher, A.R.; Espie, A.A. Permeability of the Mercia Mudstone: Suitability as caprock to carbon capture and storage sites. Geofluids 2016, 16, 26-42. [CrossRef]

38. Neufelder, R.J.; Bowen, B.B.; Lahann, R.W.; Rupp, J.A. Lithologic, mineralogical, and petrophysical characteristics of the Eau Claire Formation: Complexities of a carbon storage system seal. Environ. Geosci. 2012, 19, 81-104. [CrossRef]

39. Armitage, P.J.; Worden, R.H.; Faulkner, D.R.; Aplin, A.C.; Butcher, A.R.; Espie, A.A. Mercia Mudstone Formation caprock to carbon capture and storage sites: Petrology and petrophysical characteristics. J. Geol. Soc. 2013, 170, 119-132. [CrossRef]

40. Wedepohl, H.K. The composition of the continental crust. Geochim. Cosmochim. Acta 1995, 59, 1217-1232. [CrossRef]

41. Baines, S.J.; Worden, R.H. The long term fate of $\mathrm{CO}_{2}$ in the subsurface: Natural analogues for $\mathrm{CO}_{2}$ storage. In Geological Storage of Carbon Dioxide. Special Publication; Baines, S.J., Worden, R.H., Eds.; The Geological Society: London, UK, 2004; Volume 233, pp. 59-85.

42. Baines, S.J.; Worden, R.H. Geological storage of carbon dioxide. In Geological Storage of Carbon Dioxide. Special Publication; Baines, S.J., Worden, R.H., Eds.; Geological Society: London, UK, 2004; Volume 233, pp. 1-6. 
43. Worden, R.H.; Smith, L.K. Geological sequestration of $\mathrm{CO}_{2}$ in the subsurface: Lessons from $\mathrm{CO}_{2}$ injection enhanced oil recovery projects in oilfields. In Geological Storage of Carbon Dioxide. Special Publication; Baines, S.J., Worden, R.H., Eds.; Geological Society: London, UK, 2004; Volume 233, pp. 211-224.

44. Worden, R.H.; Morrall, G.; Kelly, S.; Mc Ardle, P.; Barshep, D.V. A renewed look at calcite cement in marine-deltaic sandstones: The Brent Reservoir, Heather Field, Northern North Sea, UK. In Application of Analytical Techniques to Petroleum Systems. Special Publication; Dowey, P.J., Osborne, M.J., Volk, H., Eds.; Geological Society: London, UK, 2019; Volume 484.

45. Daniel, R.F.; Kaldi, J.G. Evaluating seal capacity of caprocks and intraformational barriers for $\mathrm{CO}_{2}$ containment. In Carbon Dioxide Sequestration in Geological Media-State of the Science: AAPG Studies in Geology; Grobe, M., Pashin, J.C., Dodge, R.L., Eds.; American Association of Petroleum Geologists: Tulsa, OK, USA, 2009; Volume 59, pp. 335-345.

46. Kaldi, J.G.; Daniel, R.F.; Tenthorey, E.; Michael, K.; Schacht, U.; Nicol, A.; Underschultz, J.R.; Backe, G. Containment of $\mathrm{CO}_{2}$ in CCS: Role of Caprocks and Faults. Energy Procedia. 2013, 37, 5403-5410. [CrossRef]

47. Dewhurst, D.N.; Jones, R.M.; Raven, M.D. Microstructural and petrophysical characterization of Muderong Shale: Application to top seal risking. Pet. Geosci. 2002, 8, 371-383. [CrossRef]

48. Rybacki, E.; Reinicke, A.; Meier, T.; Makasi, M.; Dresen, G. What controls the mechanical properties of shale rocks?-Part I: Strength and Young's modulus. J. Pet. Sci. Eng. 2015, 135, 702-722. [CrossRef]

49. Rybacki, E.; Meier, T.; Dresen, G. What controls the mechanical properties of shale rocks?-Part II: Brittleness. J. Pet. Sci. Eng. 2016, 144, 39-58. [CrossRef]

50. Jin, X.C.; Shah, S.N.; Roegiers, J.C.; Zhang, B. An integrated petrophysics and geomechanics approach for fracability evaluation in shale reservoirs. SPE J. 2015, 20, 518-526. [CrossRef]

51. Hutcheon, I.; Shevalier, M.; Abercrombie, H.J. pH buffering by metastable mineral-fluid equilibria and evolution of carbon dioxide fugacity during burial diagenesis. Geochim. Cosmochim. Acta 1993, 57, 1017-1027. [CrossRef]

52. Deer, W.A.; Howie, R.A.; Zussman, J. An Introduction to the Rock-Forming Minerals, 3rd ed.; The Mineralogical Society: London, UK, 2013; p. 498.

53. Worden, R.H.; Griffiths, J.; Wooldridge, L.J.; Utley, J.E.P.; Lawan, A.Y.; Muhammed, D.D.; Simon, N.; Armitage, P.J. Chlorite in sandstones. Earth Sci. Rev. 2020, 204, 103105. [CrossRef] 